\title{
Will climate mitigation ambitions lead to carbon neutrality? An analysis of the local-level plans of 327 cities in the EU
}

\author{
Monica Salvia ${ }^{1,}{ }^{,}$, Diana Reckien ${ }^{2}$, Filomena Pietrapertosa ${ }^{1}$, Peter Eckersley ${ }^{3,4}$, Niki-Artemis Spyridaki ${ }^{5}$, \\ Anna Krook-Riekkola ${ }^{6}$, Marta Olazabal ${ }^{7}$, Sonia De Gregorio Hurtado ${ }^{8}$, Sofia G. Simoes ${ }^{9}$, Davide \\ Geneletti $^{10}$, Vincent Viguié ${ }^{11}$, Paris A. Fokaides ${ }^{12}$, Byron I. Ioannou ${ }^{12}$, Alexandros Flamos ${ }^{5}$, Maria \\ Szalmane Csete ${ }^{13}$, Attila Buzasi ${ }^{13}$, Hans Orru ${ }^{14,15}$, Cheryl de Boer ${ }^{2}$, Aoife Foley ${ }^{16,17}$, Klavdija Rižnar ${ }^{18}$, Marko \\ Matosović ${ }^{19}$, Mario V. Balzan ${ }^{20}$, Magdalena Smigaj ${ }^{21}$, Viera Baštáková22 ${ }^{22}$ Eva Streberova ${ }^{23}$, Nataša Belšak \\ Še $^{18}$, Lana Coste ${ }^{11}$, Léa Tardieu ${ }^{11}$, Corinna Altenburg ${ }^{24}$, Eliska Krkoška Lorencová25 ${ }^{2}$, Kati Orru ${ }^{26}$, Anja \\ Wejs $^{27,28}$, Efren Feliu ${ }^{29}$, Jon Marco Church ${ }^{30}$, Stelios Grafakos ${ }^{31}$, Sergiu Vasilie ${ }^{32}$, Ivan Paspaldzhiev ${ }^{33}$, \\ Oliver Heidrich ${ }^{34}$.
}

\section{Affiliations:}

${ }^{1}$ Institute of Methodologies for Environmental Analysis - National Research Council of Italy, C.da S. Loja, 85050 Tito Scalo (PZ), Italy

${ }^{2}$ Faculty of Geo-Information Science and Earth Observation, University of Twente, PO Box 217, 7500 AE Enschede, Netherlands

${ }^{3}$ Nottingham Trent University, 50 Shakespeare Street, Nottingham NG1 4FP, United Kingdom

${ }^{4}$ Leibniz Institute for Research on Society and Space, Flakenstraße 29-31, 15537 Erkner, Germany.

${ }^{5}$ Department of Industrial Management \& Technology, University of Piraeus (UNIPI), 80, Karaoli \& Dimitriou street, 18534 Piraeus, Greece

${ }^{6}$ Department of Engineering Sciences and Mathematics, Luleå University of Technology (LTU), Energy Science Unit, SE- 97187 Luleå, Sweden

${ }^{7}$ Basque Centre for Climate Change (BC3), Parque Científico UPV/EHU, Edificio Sede 1, Planta 1, Barrio Sarriena, s/n, 48940 Leioa, Spain

${ }^{8}$ School of Architecture, Department of Urban and Spatial Planning, Universidad Politécnica de Madrid, Avenida de Juan de Herrera, 4, 28040 Madrid, Spain

${ }^{9}$ The National Energy Laboratory of Portugal (LNEG), Unit on Resource Economics, Estrada da Portela, Bairro do Zambujal Ap 7586, 2720-999 Amadora, Portugal

${ }^{10}$ Department of Civil, Environmental and Mechanical Engineering, University of Trento, Via Mesiano 77, 38123 Trento, Italy

${ }^{11}$ Centre International de Recherche sur l'Environnement et le Développement (CIRED). 45bis, Av de la Belle Gabrielle, F-94736 Nogent-sur-Marne, France

${ }^{12}$ School of Engineering, Frederick University, 7, Frederickou Str., 1036 Nicosia, Cyprus

${ }^{13}$ Budapest University of Technology and Economics, Department of Environmental Economics, Magyar tudósok körútja 2 Budapest H-1117, Hungary

${ }^{14}$ Institute of Family Medicine and Public Health, University of Tartu, Ravila 19, 51007 Tartu, Estonia

${ }^{15}$ Department of Public Health and Clinical Medicine, Umea University, Umeå universitet, 90187 Umea, Sweden 
${ }^{16}$ Queen's University Belfast, School of Mechanical \& Aerospace Engineering, Ashby Building, Stranmillis Road, Belfast BT9 5AH, United Kingdom

${ }^{17}$ Department of Civil, Structural \& Environmental Engineering, Trinity College Dublin, Ireland

${ }^{18}$ SRC Bistra Ptuj, Slovenski trg 6, 2250 Ptuj, Slovenia

${ }^{19}$ PwC Savjetovanje, Heinzelova 70, 10000 Zagreb, Croatia

${ }^{20}$ Institute of Applied Sciences, Malta College of Arts, Science and Technology, Paola PLA9032, Malta

${ }^{21}$ Faculty of Agriculture, Kyushu University, 744 Motooka, Fukuoka 819-0395, Japan

${ }^{22}$ SlovakGlobe: Slovak University of Technology and Slovak Academy of Sciences, Vazovova 5, 81243 Bratislava, Slovakia

${ }^{23}$ Office of the Chief Architect of the City of Bratislava, Uršulínska 440/6, 81101 Bratislava, Slovakia

${ }^{24}$ German Institute of Urban Affairs (Difu), Dept. of Environment, 10969 Berlin, Germany

${ }^{25}$ Global Change Research Institute of the Czech Academy of Sciences, Bělidla 986/4a, 60300 Brno, Czech Republic

${ }^{26}$ Institute of Social Studies, University of Tartu, Lossi 36, 50090 Tartu, Estonia

${ }^{27}$ NIRAS A/S, Østre Havnegade 12, 9000 Aalborg, Denmark

${ }^{28}$ Department of Planning, Aalborg University, Rendsburggade 14, 9000 Aalborg, Denmark

${ }^{29}$ TECNALIA. Energy and Environment Division, Parque Tecnológico de Bizkaia, Astondo Bidea, edificio 700c/ Geldo, 48160 Derio, Spain

${ }^{30}$ Université de Reims, 57 rue Pierre Taittinger, 51571 Reims Cedex, France

${ }^{31}$ Institute for Housing and Urban Development Studies, Burgemeester Oudlaan 50, 3062 PA, Rotterdam, the Netherlands

${ }^{32}$ Denkstatt Romania SRL, Str. Madrid nr.22, 300391 Timisoara, Romania

${ }^{33}$ Denkstatt Bulgaria Ltd, 115 Arsenalski blvd ent. 1, fl. 5, app. 7, 1421 Sofia, Bulgaria

${ }^{34}$ School of Engineering, Tyndall Centre for Climate Change Research, Newcastle University, Newcastle upon Tyne, NE1 7RU, United Kingdom

* = Corresponding author: Dr. Monica Salvia, Institute of Methodologies for Environmental Analysis National Research Council of Italy (CNR-IMAA), C.da S.Loja, 85050 Tito Scalo (PZ), Italy. E-mail: monica.salvia@imaa.cnr.it, Tel: +390971 427207. 


\begin{abstract}
Cities across the globe recognise their role in climate mitigation and are acting to reduce carbon emissions. Knowing whether cities set ambitious climate and energy targets is critical for determining their contribution towards the global $1.5^{\circ} \mathrm{C}$ target, partly because it helps to identify areas where further action is necessary. This paper presents a comparative analysis of the mitigation targets of 327 European cities, as declared in their local climate plans. The sample encompasses over $25 \%$ of the EU population and includes cities of all sizes across all Member States, plus the UK. The study analyses whether the type of plan, city size, membership of climate networks, and its regional location are associated with different levels of mitigation ambition. Results reveal that $78 \%$ of the cities have a GHG emissions reduction target. However, with an average target of $47 \%$, European cities are not on track to reach the Paris Agreement: they need to roughly double their ambitions and efforts. Some cities are ambitious, e.g. $25 \%$ of our sample (81) aim to reach carbon neutrality, with the earliest target date being 2020 . $90 \%$ of these cities are members of the Climate Alliance and $75 \%$ of the Covenant of Mayors. City size is the strongest predictor for carbon neutrality, whilst climate network(s) membership, combining adaptation and mitigation into a single strategy, and local motivation also play a role. The methods, data, results and analysis of this study can serve as a reference and baseline for tracking climate mitigation ambitions across European and global cities.
\end{abstract}

\title{
Highlights
}

- $78 \%$ of cities have a mitigation plan with targets (avg. $47 \%$ GHG reduction)

- Only $25 \%$ of cities strive for carbon neutrality, most by 2050, avg. by 2045

- $90 \%$ of cities striving for carbon neutrality are members of a climate network

- Ambition is driven by city size, climate networks, M-A combination, local motivation

- European cities must double their ambitions to meet the aims set by the Paris Agreement

Keywords: Local climate plans, cities, mitigation, energy policy, Europe, EURO LCP Initiative

Word count: 7637 words (excluding title, author names and affiliations, keywords, abbreviations, table/figure captions, acknowledgements and references)

\section{List of abbreviations}

BEI - Baseline Emission Inventory

C40 - The C40 Cities Climate Leadership Group

CNCA - Carbon Neutral Cities Alliance

$\mathrm{CO}_{2}$ - Carbon Dioxide

$\mathrm{CO}_{2} \mathrm{eq}$ - Carbon Dioxide Equivalent

CoM - Covenant of Mayors for Climate and Energy 
$\mathrm{CN}$ - Carbon Neutral

DG REGIO - Directorate-General for Regional and Urban Policy

EE - Energy Efficiency

EU - European Union

EURO-LCP Initiative -European Initiative on the study of Local Climate Plans

EUROSTAT - European Statistics Office

GCoM - Global Covenant of Mayors for Climate and Energy

GDP - Gross Domestic Product

GHG - Greenhouse gases

IPCC - Intergovernmental Panel on Climate Change

LED - Light Emitting Diode

LCP - Local Climate change Plan

M-A - Mitigation - Adaptation

M-LCP - Local Climate change Mitigation Plan

MS - Member States

NUTS - Nomenclature of Territorial Statistical Units (Nomenclature des Unités Territoriales Statistiques)

RES - Renewable Energy Sources

SEAP - Sustainable Energy Action Plan

SECAP - Sustainable Energy and Climate Action Plan

UA - Urban Audit

UN - United Nations

UK - United Kingdom 


\section{Introduction}

Signatories to the 2015 Paris Agreement pledged to reduce greenhouse gas (GHG) emissions to contain global warming below $2^{\circ} \mathrm{C}$, aiming at reducing it further to $1.5^{\circ} \mathrm{C}$ relative to pre-industrial levels. Such an ambitious target requires reaching zero emissions (hereafter referred to as carbon neutrality) by 2050 [1]. Carbon neutrality has a range of definitions and it is important to have a shared understanding [2]. The PAS 2060 [3] considers carbon neutrality to be a situation in which there are no net greenhouse gases emissions during a specified period. The Carbon Neutral Cities Alliance (CNCA) [4] defines it as ambition "to cut greenhouse gas emissions by $80-100 \%$ by 2050 or sooner", compared to the baseline year of 1990 . Both are similar in the sense that the net greenhouse gas emissions associated with a city should be zero at some point over a specified period in the future. For practical reasons and quantification, we here use a GHG reduction target of at least $90 \%$ as a definition for climate neutrality (the average between 80 $100 \%)$.

In order to reach carbon neutrality, the Intergovernmental Panel on Climate Change (IPCC), in its Special Report on Global Warming of $1.5^{\circ} \mathrm{C}$ [1], clearly states the importance of a multi-pronged approach based on: phasing out fossil fuels, using renewable energy sources (RES), facilitating behaviour change, improving energy efficiency (EE) for both supply and demand, and introducing negative emissions measures. It also highlights the relevance of implementing these measures in cities.

Since the Paris Agreement, countries have passed legislation pledging to reach climate neutrality by 2050 or earlier, including Sweden [5], France [6], the UK [7] , New Zealand [8] and Costa Rica [9]. The European Union (EU) has also set ambitious climate and energy targets. The Resolution on Climate Change of the European Parliament endorsed a net-zero GHG emissions target by 2050 in March 2019 and "urged Member States to do the same as part of the Future of Europe" [10] . Moreover, the EU set intermediate targets for 2030: to reduce GHG emissions by at least $40 \%$, to ensure that at least $32 \%$ of the consumed energy is generated from RES and to improve EE by at least $32.5 \%$ compared with business as usual [11] .

On the path towards carbon neutrality, national governments need support from public bodies at all jurisdictional levels, as well as non-state [12-14] and other societal actors (e.g. [15-17]). The implementation and enforcement of high-level policies will be jeopardised if sub-national bodies and nonstate actors lack commitment or capacity. Insufficient coordination between different governance actors may also prevent local actors from responding effectively to emerging threats $[18,19]$.

Despite these potential constraints, municipalities across the globe have recognized their key role in global climate mitigation [20-22] and committed to reduce emissions and achieve carbon neutrality. At the end of the UN's Climate Action Summit in 2019, “over 100 cities - including many of the world's largest announced significant and concrete new steps to combat the climate crisis" [23].

Yet, precisely how cities seek to lead on climate change mitigation action is less clear. Scientific literature often critiques cities for not sufficiently engaging in the climate fight or not being ambitious enough $[24,25]$. However, partly due to a lack of macro-studies that examine the efforts of numerous studies across multiple countries, there is currently limited evidence to support these claims.

Previous studies into the availability of local climate plans in Europe [26] have found a mixed picture: cities in Northern and Central Europe are far more likely to develop detailed plans compared with their counterparts elsewhere. In some cases, this was linked to the national regulatory framework, because municipalities in some countries are legally required to produce climate plans (e.g. in France and, previously, England). In Sweden (all municipalities), Italy (cities > 50,000 inhabitants) and Slovakia 
(municipalities $>2,500$ inhabitants meeting particular conditions regarding energy suppliers/ customers in the area), municipalities are obliged to develop energy plans by national legislation but these plans very often do not set targets on GHG emission reduction. In other countries, municipalities have financial support from higher tiers of government to develop energy and climate mitigation plans (e.g. Germany). This suggests that both national legislation as well as city size are important.

Cities that have made international commitments and/or joined transnational municipal networks may also be more likely to engage in climate action [26-28]. The Climate Alliance for example, which represents more than 1,500 local authorities in 17 European countries, commits its members to reduce their $\mathrm{CO}_{2}$ emissions by $10 \%$ every 5 years and to halve them by 2030 at the latest [29]. C40 Cities Climate Leadership Group (C40) connects more than 96 of the world's largest cities to act on the climate and comply with the Paris Agreement. C40 member cities are required to set a target for reducing GHG emissions "from the current level of 5.3 tonnes $\mathrm{CO}_{2}$ per person to around 2.9 tonnes by 2030 and to zero by 2050" [30]. Signatory cities of the Covenant of Mayors aim to achieve a 40\% reduction of GHG emissions by 2030 and adopting a joint approach to tackle mitigation and adaptation to climate change in a single strategy [31]. The Carbon Neutral Cities Alliance (CNCA) [4] supports cities to work together "to cut greenhouse gas emissions by $80-100 \%$ by 2050 or sooner".

The development of sector specific climate mitigation strategies and initiatives, which are then integrated into a single overarching strategy, may also be more effective in tackling climate change because this approach can help to identify synergies and tradeoffs between related initiatives [16] [32]. In this sense, we might expect unified or mainstreamed climate strategies, which combine mitigation and adaptation actions into a single document, to be more successful than disparate or separate documents [33-36].

This paper addresses the question of whether cities' climate mitigation targets are ambitious enough to meet the Paris Agreement, i.e. reach carbon neutrality by 2050 or sooner. To do so, it draws on previous evidence related to city size, climate network membership, and climate policy governance issues and their connection to climate ambition. In this study, ambition is defined with reference to the GHG emissions reduction targets that cities aim to achieve. The highest ambition is defined by targeting at least $80 \%$ $100 \%$ of GHG emissions reduction, i.e. by reaching carbon neutrality, by 2050 or sooner.

The rest of this paper identifies the main trends and patterns in the climate change mitigation policies and targets of EU cities, as published in their Local Climate Plans (LCPs). Previous work on assessing and understanding urban climate policy progress in European cities-what hereafter is called the EURO-LCP initiative $[26,32,37]$ - has been taken into consideration. We examine a representative sample of 327 cities across $28 \mathrm{EU}$ countries (total number of EU MS at the time of data collection) and their climate change mitigation policies. Data, i.e. the availability of LCPs with contents on mitigation (M-LCPs hereafter) was updated between November 2018 and December 2019. This study advances the quantification of the climate ambition of European cities and provides an analysis of contextual factors that relate to it. More importantly, our work aims to understand the spatial levels at which climate policy is being shaped within the EU and to assist in identifying the extent to which the climate planning process is moving at different speeds in different parts of Europe.

In summary the paper addresses three issues, it: 1) analyses ambitions according to the type of plan, city size, the combination of adaptation and mitigation aspects in a single strategy and membership of climate networks, 2) performs a comparative assessment of these aspects across cities, European countries and regions, and 3 ) identifies whether the climate targets of this representative sample of EU cities are ambitious enough to reach the Paris Agreement. 
The paper is structured in 5 sections. Following this introduction, a description of the city sample, M-LCPs data collection and analytical framework is provided in Section 2. Results on types of M-LCPs, energy and climate targets and transnational municipal networks are included in Section 3. Section 4 critically discusses the results achieved in this study, and Section 5 concludes.

\section{Data and methods}

\subsection{The city sample}

This study is based on a sample of 327 core cities within the EU-28 (the UK was still a member of the EU when we collected our data), covered by the Cities Statistics database of the European Statistics Office (Eurostat), formerly known as "Urban Audit" (UA) [39]. The UA database was developed with the aim of comparing data across European urban areas. The UA sample is a representative sample of currently more than a thousand core cities, larger urban zones and metropolitan areas across the EU-28. The sample has fluctuated slightly while steadily increasing over the past years and the chosen sample of 327 core cities is mentioned in the Eurostat Regional Yearbook 2011 [40]. It has been chosen because of its smaller size (as compared to the 885 cities currently belonging to the whole Cities Statistics database selection) and its representativeness.

The UA city sample is representative in size and regional distribution per country as it uses the following criteria [41]: (i) at least $20 \%$ of the population is covered in each country, (ii) at least one city from each NUTS3 Region is included to ensure a balanced geographical distribution, and (iii) varied city sizes are considered by including large and medium (above 50,000 inhabitants) as well as small cities (below 50,000 inhabitants). Considering the most recent data on EU-28 population (513.5 million inhabitants [42]), the city sample covers 128.8 million inhabitants, that is $25.1 \%$ of the total EU-28 population, ranging from $14.3 \%$ in Portugal to $55.9 \%$ in Malta.

Data collection for the City Statistics is a joint effort by the Directorate-General for Regional and Urban Policy (DG REGIO), the National Statistical Institutes and Eurostat. More information on this database can be found in the Cities Statistics database itself [39] and in supporting documents [41-43]. Figure 1 presents a map of the location of the 327 core cities considered in this paper. 


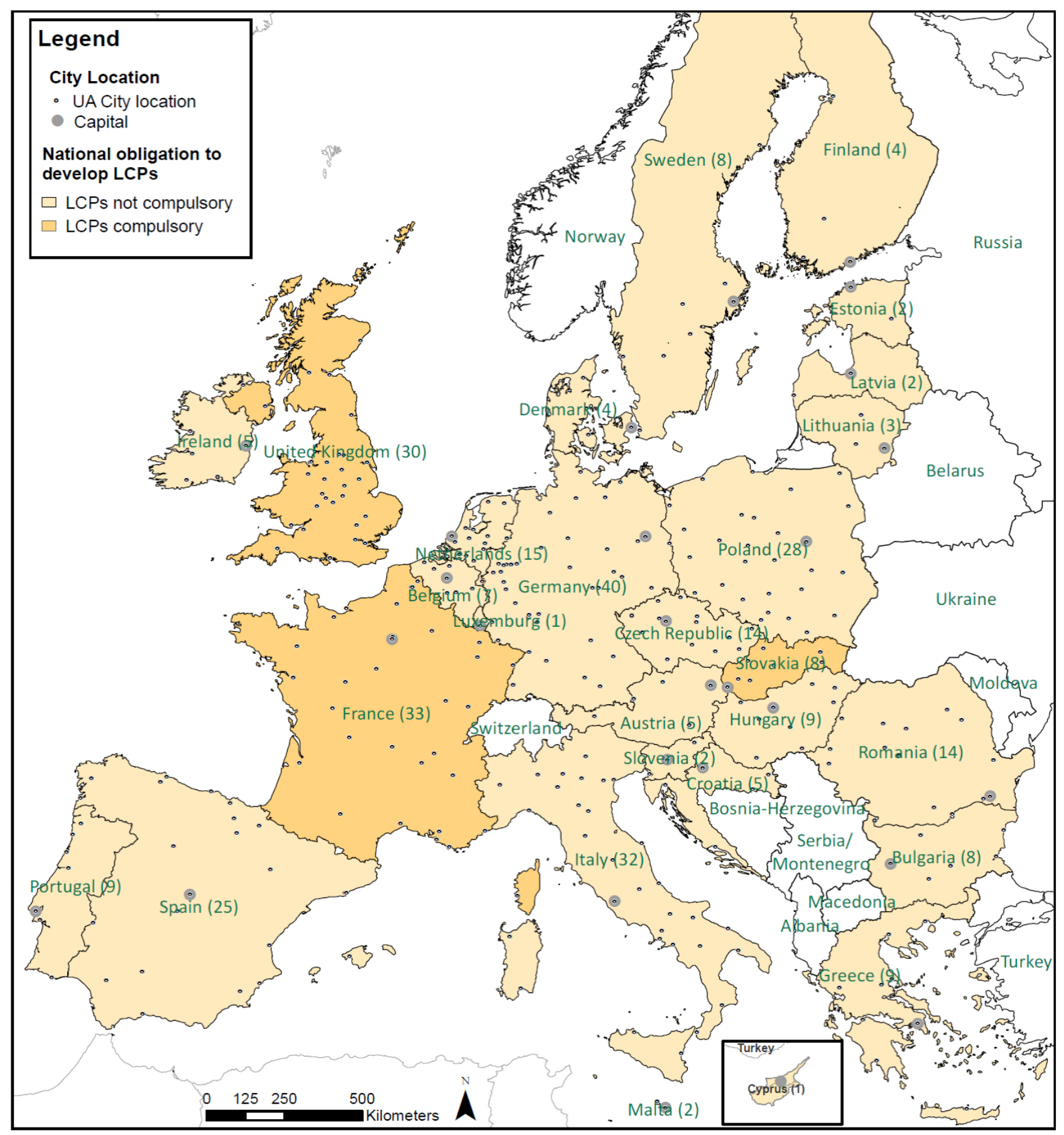

Figure 1: Map of the location of the 327 core cities of the Eurostat Urban Audit database [39] underlying this study, showing the share of larger cities per country as country shading. Larger city is defined as above 250,000 inhabitants. Data: resident population as of $1^{\text {st }}$ January of latest year available (2011 to 2017), depending on city and country from Eurostat (2019), except Fareham (UK), Spijkenisse (NL), and Croatia (Wikipedia; no data on Eurostat at the respective time of download).

\subsection{Identification of local climate change mitigation plans and strategies}

For the identification of local climate change mitigation plans and strategies (M-LCPs), an approach similar to the one described in Reckien et al. [26] was used:

- Between November 2016 and January 2017, a team of native or fully proficient language authors compiled a database of M-LCPs for each sample city and EU-28 country. This database was 
facilitated using desk/web review and prominent keyword searches in each national language [26,32], complemented with direct contact with local authorities (when further information and/or clarifications were needed). The list of plans [32] was re-checked and if necessary, updated between November 2018 and November 2019. All relevant plans and strategies were downloaded and saved.

- Both binding (officially adopted) and non-binding plans were considered, on the basis that the process of developing a M-LCP (and not only its adoption) implies a level of awareness and sensitivity for action. In all cases the respective plan or policy had to be (made) available.

Following Reckien et al. [26,32], the M-LCP were classified into three main types (Figure 2): "Type A" corresponding to dedicated M-LCPs, "Type B" for horizontally mainstreamed (i.e. cross-sectoral, respecting interactions between different policy fields and aiming for broader goals than climate change), and "Type C" for vertically mainstreamed (i.e. sector plans such as for the energy sector). We further differentiated between autonomously developed (A1) or legally required plans (A2), or plans driven by an international organization (A3) such as the Covenant of Mayors. This common typology allows for a better comparison of the plans and their content across European cities, assuming a higher degree of similarity of plans, institutional guidelines, national framework documents, financing or support, etc.

This study focused on climate networks that are particularly relevant to EU cities and that make it mandatory for participating cities to define a climate action plan and to achieve minimum targets of for reducing GHG emissions. These networks are: Climate Alliance, C40 Cities Climate Leadership Group (C40), Covenant of Mayors (for Climate and Energy), and the Carbon Neutral Cities Alliance (CNCA). Information on the formal adhesion of cities to these international urban networks (step I of the overall step-by-step process, as defined in the CoM guidelines [44]) was retrieved from the organization's website in November/December 2019. Afterwards, the climate plans developed in this context (step II) were accessed and were cross-checked with those that the cities may have already published. By comparing cities across Europe that were and were not members of such networks, this approach also enabled an analysis of their possible role in shaping urban climate planning. 


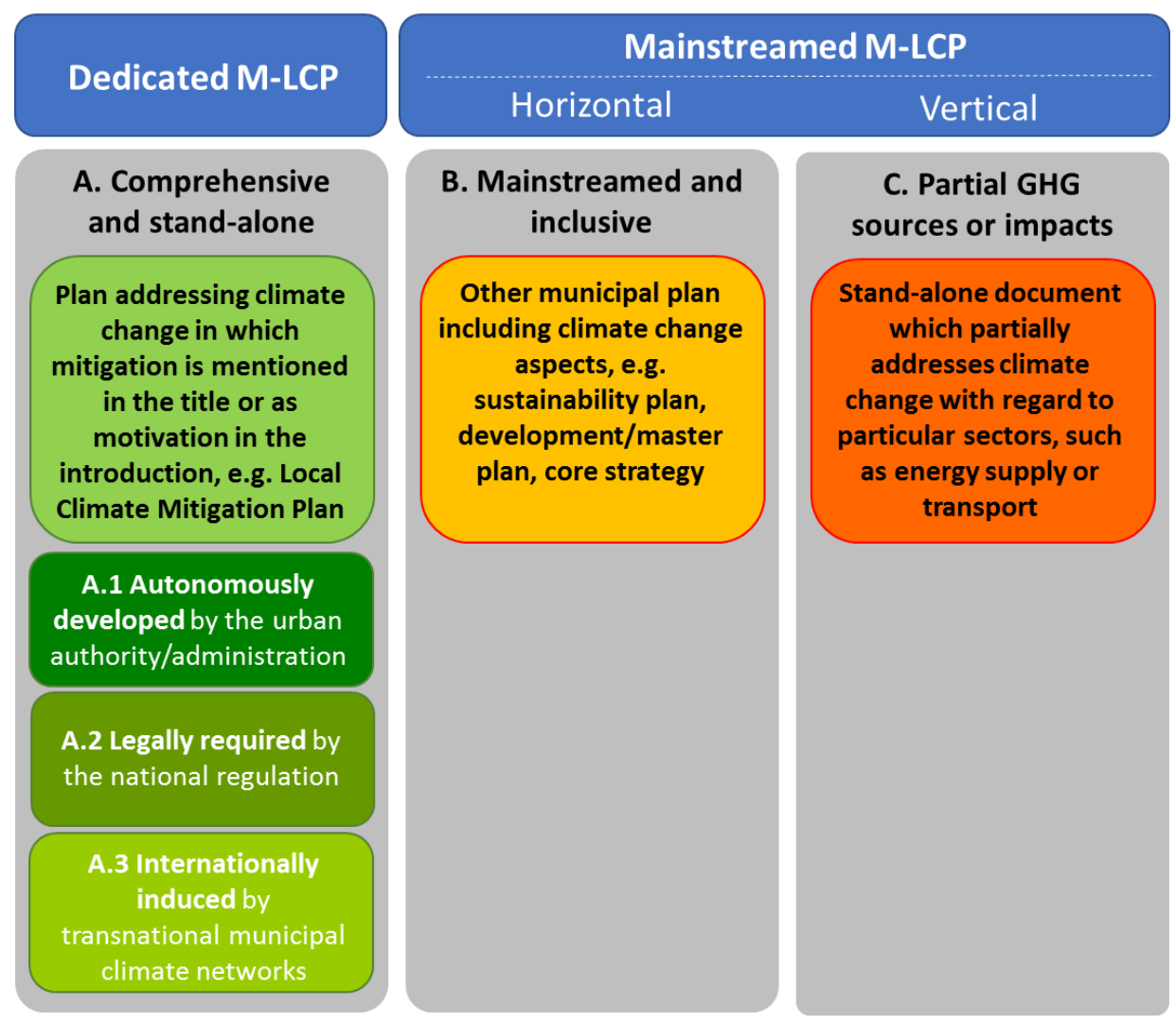

Figure 2: Typology of local climate change mitigation plans (modified after [32]).

In this study, only one plan was analysed for each city in the sample, where available. Priority was given to M-LCP belonging to Type A (dedicated, comprehensive and stand-alone). If such a plan was available, it was considered for the analysis. Comprehensive and stand-alone plans developed in countries where national legislation requires urban climate planning were automatically assigned as $A 2$, rather than $A 1$. Type $B$ and Type $C$ plans were considered only if no Type $A$ plans were available for the city. Thus, each city was assigned with the plan most focused on climate mitigation (available at the time of searching). This approach is in line with the one adopted by Reckien et al. [26,32].

\subsection{Content analysis of the Mitigation LCPs}

In order to identify whether, and how, local governance planning practices align with cities' mitigation efforts and ambition, the list of M-LCPs included in Reckien et al. [26] was first updated and then analysed according to its content based on an approach similar to that used in Reckien et al. [37]. Thus, the content of each M-LCP was extracted based on a common structure organized in the following sections: general information (name, city and type of plan); mitigation aspects (including details of the emissions inventory, type and magnitude of the emissions targets, types of mitigation measures, implementation and followup); energy targets (type and magnitude of energy efficiency and RES targets); the combination of mitigation and adaptation in the same plan; and governance issues regarding information on how the plan was developed. Table 1 provides a detailed list of information collected through the online questionnaire utilized in this study.

All data and information gathered through the questionnaire were analysed in order to shed light on the main types of local climate mitigation plans (M-LCPs) currently available, on their geographical distribution across Europe and in relation to city size. The main short- and medium-term energy and climate targets were identified, as well as cities' membership of the main international climate networks. 
Table 1: Key information collected and utilized for this study for each city/ M-LCP.

\begin{tabular}{|c|c|}
\hline Type of contents & Compiled information for Mitigation Local Climate Plan (M-LCP) \\
\hline General information & $\begin{array}{l}\text { - Name of the analyst and date and time at which the analysis was } \\
\text { undertaken } \\
\text { - Country and respective national climate change mitigation target } \\
\text { - Name of the Local Climate Action Plan and the city } \\
\text { - Place where the plan was found and URL (if applicable) } \\
\text { - Type of M-LCP (A, B, C or D) } \\
\text { - Legal status of the M-LCP, year of adoption, approval and/ or publication, } \\
\text { the existence of a previous plan and respective year of adoption } \\
\text { - Existence of previous M-LCP and adoption year } \\
\text { - Combination of mitigation and adaptation aspects in the same document } \\
\text { (total pages of the mitigation section and total pages of the document) }\end{array}$ \\
\hline GHG emissions inventory & $\begin{array}{l}\text { - Existence of a baseline emissions inventory } \\
\text { - Baseline year } \\
\text { - Type of accounting for the emissions reduction: } \mathrm{CO}_{2} \text { or } \mathrm{GHGs} / \mathrm{CO}_{2} \mathrm{eq} / \\
\mathrm{CO}_{2} \mathrm{e} / \mathrm{CDE} \text { (specifying the included gases) }\end{array}$ \\
\hline GHG emissions targets & $\begin{array}{l}\text { - Specification of the emissions target(s): the numeric value), the unit (e.g. \% } \\
\text { or metric tons), and the target (e.g. year or scenario) } \\
\text { - Indication whether carbon neutrality is explicitly listed as an objective and } \\
\text { if so by which year } \\
\text { - Existence of other emissions reduction targets, e.g. sector targets } \\
\text { - Sectors for which the M-LCP aims to implement mitigation measures: } \\
\text { energy use; energy efficiency and saving; renewable energy; buildings; } \\
\text { transport;, waste; nature-based solutions; agriculture and food; land-use; } \\
\text { carbon sequestration; industry; consumption and behaviour; policy and } \\
\text { research; education; communication and public relations; other. }\end{array}$ \\
\hline Energy targets & $\begin{array}{l}\text { - Existence of explicit target(s) for energy efficiency (value, unit and target } \\
\text { year) } \\
\text { - Existence of explicit target(s) for renewable energy (value, unit and target } \\
\text { year) }\end{array}$ \\
\hline
\end{tabular}

\subsection{Statistical analysis}

To investigate the relationships between mitigation targets and urban population, climate membership, type of plan and integration level (combination of adaptation and mitigation aspects in one plan) descriptive statistics and correlation analysis were conducted. For the correlation analysis bivariate, non-parametric, two-tailed tests were employed based on Kendalls-tau-b [45]. Additionally, partial, twotailed correlations were used to control for potential confounding factors, i.e. covariates [46], which is necessary for variables that seem highly correlated with the descriptors. The statistical analysis was conducted with IBM SPSS Statistics Package 2.

\section{Results}

\subsection{Emissions reduction targets}

The study reveals that 254 (78\%) of the 327 cities in the sample have a climate change plan with mitigation targets, i.e. $73(22 \%)$ of them do not have a plan or have a plan without targets (Table 2; CO2_GHG_CN_target). More than half of the cities, i.e. 154 cities (61\%) that include targets in their plans, 
report on $\mathrm{CO}_{2}$ emissions; the remaining 100 cities (39\%) base their calculations on $\mathrm{GHG}$ emissions or $\mathrm{CO}_{2}$ equivalents ( $\left.\mathrm{CO}_{2} \mathrm{eq}\right) . \mathrm{CO}_{2}$ targets are used in all the analysed M-LCPs of Belgium, Croatia, Cyprus, Czech Republic, Estonia, Latvia, Lithuania, the Netherlands, Portugal, Romania and Slovakia, whereas GHG targets are referred to as $\mathrm{CO}_{2} \mathrm{eq}$ in all the analysed plans of Austria, Bulgaria, Denmark and Finland. In the remaining countries, some cities refer to $\mathrm{CO}_{2}$ while others to $\mathrm{CO}_{2}$ eq.

The basis of accounting does not distort the ambition; the targets of both accounting methods have similar spreads (reduction targets for $\mathrm{CO}_{2}$ range from 2-100\%, whereas for $\mathrm{CO}_{2} \mathrm{eq}$ they range from 3-100\%) and averages (39.45\% versus $39.57 \%$, respectively). Also, the chosen timelines are similar. Plans based on $\mathrm{CO}_{2}$ accounting start in 1990-2015 as a baseline and go until the year 2019-2050; plans based on GHG accounting refer to a baseline of 1990-2020 and a target year of 2020-2050, respectively (Table 2).

Table 2: Descriptive statistics of local mitigation targets and cities' characteristics.

\begin{tabular}{|c|c|c|c|c|c|c|}
\hline & No. & Minimum & Maximum & Sum & Mean & Std. Deviation \\
\hline \multicolumn{7}{|l|}{ Targets: } \\
\hline Max_CO2_target & 154 & 2 & 100 & - & 39.45 & 25.60 \\
\hline BaselineYearCO2 & 156 & 1990 & 2015 & - & 2002 & 8.42 \\
\hline TargetYearCO2 & 154 & 2019 & 2050 & - & 2027 & 11.12 \\
\hline Max_GHG_target & 100 & 3 & 100 & - & 39.57 & 28.48 \\
\hline BaselineYearGHG & 100 & 1990 & 2015 & - & 2003 & 8.52 \\
\hline TargetYearGHG & 100 & 2020 & 2050 & - & 2027 & 11.44 \\
\hline Max_CO2_GHG_target & 253 & 2 & 100 & - & 39.55 & 26.75 \\
\hline Carbon_neutrality & 252 & 0 & 1 & 81 & .32 & .47 \\
\hline TargetYearCarbonNeutrality & 80 & 2,020 & 2,050 & - & 2045 & 8.89 \\
\hline CO2_GHG_CN_target & 254 & 2 & 100 & - & 47.15 & 31.40 \\
\hline \multicolumn{7}{|l|}{ City characteristics: } \\
\hline Population & 327 & 17,163 & $9,803,494$ & $128,849,797$ & $394,036.08$ & $802,497.00$ \\
\hline CoM & 327 & 0 & 1 & 215 & .66 & .47 \\
\hline CA & 327 & 0 & 1 & 46 & .14 & .35 \\
\hline $\mathrm{C} 40$ & 327 & 0 & 1 & 15 & .05 & .21 \\
\hline AM_Combi & 254 & 0 & 1 & 79 & .31 & .46 \\
\hline TypeA1 & 254 & 0 & 1 & 114 & .45 & .50 \\
\hline TypeA2 & 254 & 0 & 1 & 37 & .15 & .35 \\
\hline TyреА3 & 254 & 0 & 1 & 93 & .37 & .48 \\
\hline TyреВ & 254 & 0 & 1 & 1 & .00 & .06 \\
\hline TypeC & 254 & 0 & 1 & 9 & .04 & .18 \\
\hline
\end{tabular}

Note: The study distinguishes three categories of targets based on the method of emissions accounting and the height of the target. The first category refers to cities with a maximum target that is based on $\mathrm{CO}_{2}$ and reaches up to $<80 \%$. The second category refers to cities with a maximum target that is based on $\mathrm{GHG}\left(\mathrm{CO}_{2} \mathrm{eq}\right)$ and reaches up to $<80 \%$. The first and the second category of targets are combined in Max_CO2_GHG_targets. The third category refers to cities with carbon neutrality targets, being based on either $\mathrm{CO}_{2}$ or $\mathrm{GHG}\left(\mathrm{CO}_{2}\right.$ eq), defined by targets of 80$100 \%$. All three categories of targets are combined in CO2_GHG_CN_targets. Each target category has a baseline year (except carbon neutrality, as it is negligible from which baseline you start when you want to reduce emissions to near zero) and a target year. Key: CoM - Covenant of Mayors; AM_Combi - Combination of adaptation and mitigation issues in one LCP.

Figure 3 shows that a plurality of the M-LCPs that do not commit to climate neutrality have a reduction target of less or equal to $20 \%$. This represents $29.5 \%$ of the analysed plans with a $\mathrm{CO}_{2}$ emissions target (Figure 3.a) and $42.4 \%$ of plans with a $\mathrm{CO}_{2}$ eq target (Figure 3.b), respectively (though referring to different years). Most of these cities show an initial, yet modest, commitment towards mitigation, probably influenced by the European 20-20-20 goal or the Covenant of Mayors minimum requirement. One example is Poland-most of its cities have set targets smaller than $20 \%$. The rest of the targets are spread relatively evenly with lower values observed for the intermediate target of 31-40\%. 


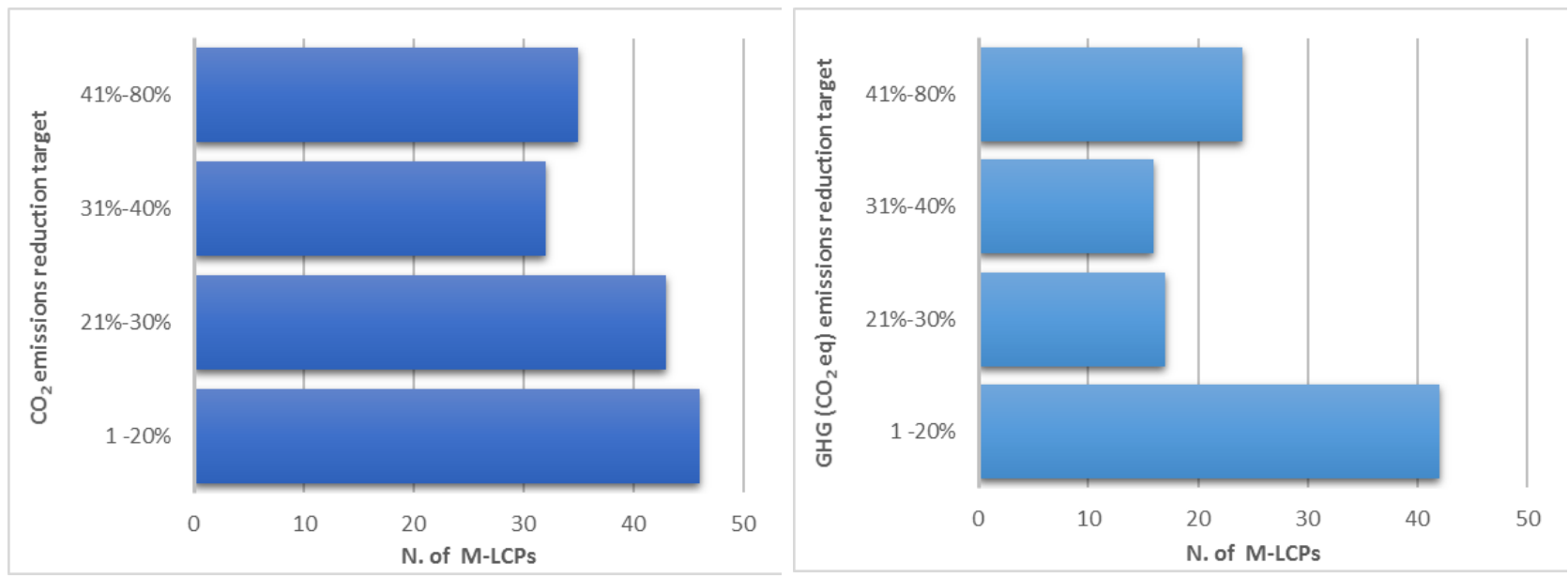

a)

Figure 3: Number of M-LCPs by range of $\mathrm{CO}_{2}(\mathrm{a})$ and GHG $\left(\mathrm{CO}_{2}\right.$ eq) (b) reduction target (baseline years: 1990-2015, target years: 2020-2040). Please note that this excludes mitigation targets equal to and higher than $80 \%$, as these are regarded as a goal for climate neutrality and reported further down.

Figure 4 (a-d) shows the distribution of the $254 \mathrm{M}$-LCPs in the sample across typologies (i.e. Type A1, A2, $\mathrm{A} 3, \mathrm{~B}$ and $\mathrm{C}$ ), level of emissions reduction targets (\% y-axis), type of emissions targets (i.e. $\mathrm{CO}_{2}$ or $\mathrm{GHG}$ target) and regional distribution in Europe (Northern or Southern Europe $)^{1}$. Again, the figures exclude cities with targets of $80 \%$ and above.

The figure highlights that comprehensive autonomous and nationally induced plans (i.e. Type A1 \& A2 plans) developed by Northern European cities show the greatest variance in their level of ambition, with $\mathrm{CO}_{2}$ emissions reduction targets ranging from $2 \%$ to $60 \%$ (Figures $4 a$ ) and $\mathrm{GHG}$ emissions targets ranging from $4 \%$ to $75 \%$ (Figure 4 b). Polish cities with type A1 plans have the lowest ambitions (i.e. targets below 20\%), while cities in Germany (Bochum, Berlin, Schwerin), the Netherlands (Eindhoven), France (Ajaccio, Tours and Besançon), and UK (London) have the highest ambition levels (i.e. targets greater than or equal to $60 \%)$.

Type A3 plans demonstrate a consistent pattern and a lower level of ambition, ranging from $20 \%$ to $60 \%$ (with the sole exception of the Finnish city of Turku, which has a $65 \%$ mitigation target), irrespective of their geographical location or type of mitigation target. Figure 4c shows how these plans, developed within international climate networks, play a predominant role in Southern European cities. Type $C$ plans have a similar range as $\mathrm{A} 3$ plans (i.e. $20 \%$ to $60 \%$ ), are mainly developed in Northern European countries and include $\mathrm{CO}_{2}$ targets (Figure 4a).

In general, Southern European cities are less ambitious than their Northern European counterparts; the maximum target in these countries is $42 \%$, except for the cities of Seville and Lisbon which aim to reduce their emissions by $54 \%\left(\mathrm{CO}_{2} \mathrm{eq}\right)$ and $60 \%\left(\mathrm{CO}_{2}\right)$, respectively. This suggests that Southern European cities have mainly developed SEAPs/SECAPs when joining the Covenant of Mayors, albeit with mitigation targets that are less ambitious than Northern European cities.

\footnotetext{
${ }^{1}$ Cities in Italy, Spain, Portugal, Slovenia, Croatia, Bulgaria, Greece, Cyprus and Malta were categorized as Southern European (SE) cities. The rest of the cities in our sample were categorized as Northern European (NE) cities.
} 


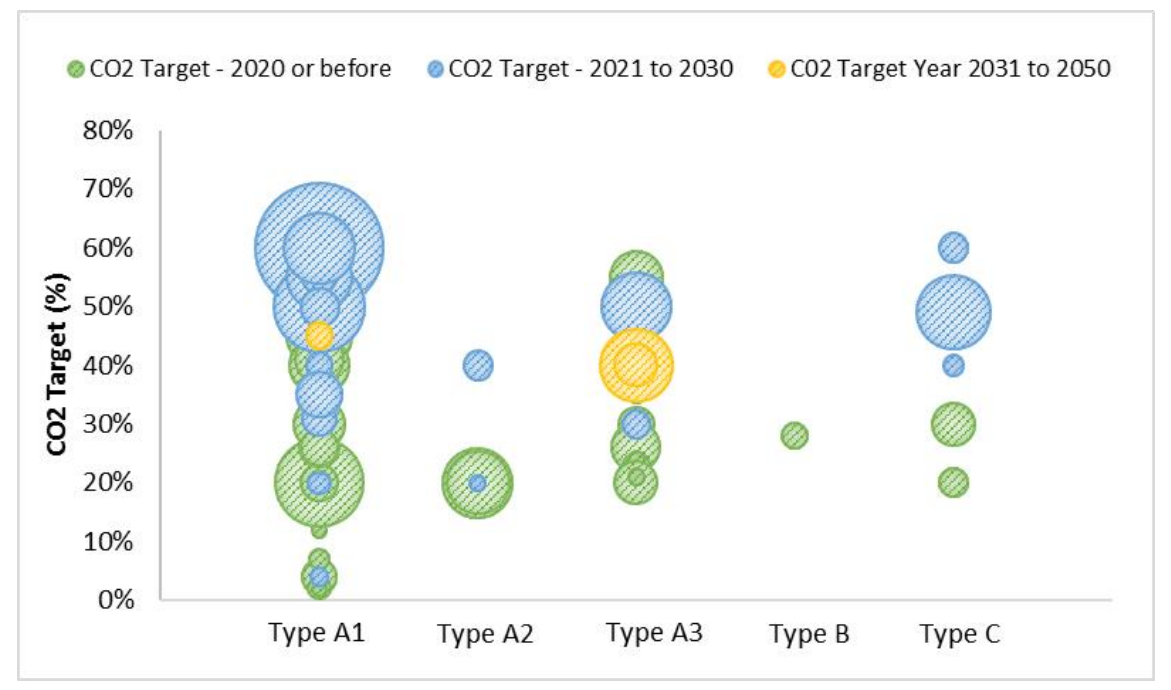

a) M-LCPs with $\mathrm{CO}_{2}$ targets in Northern European (NE) cities

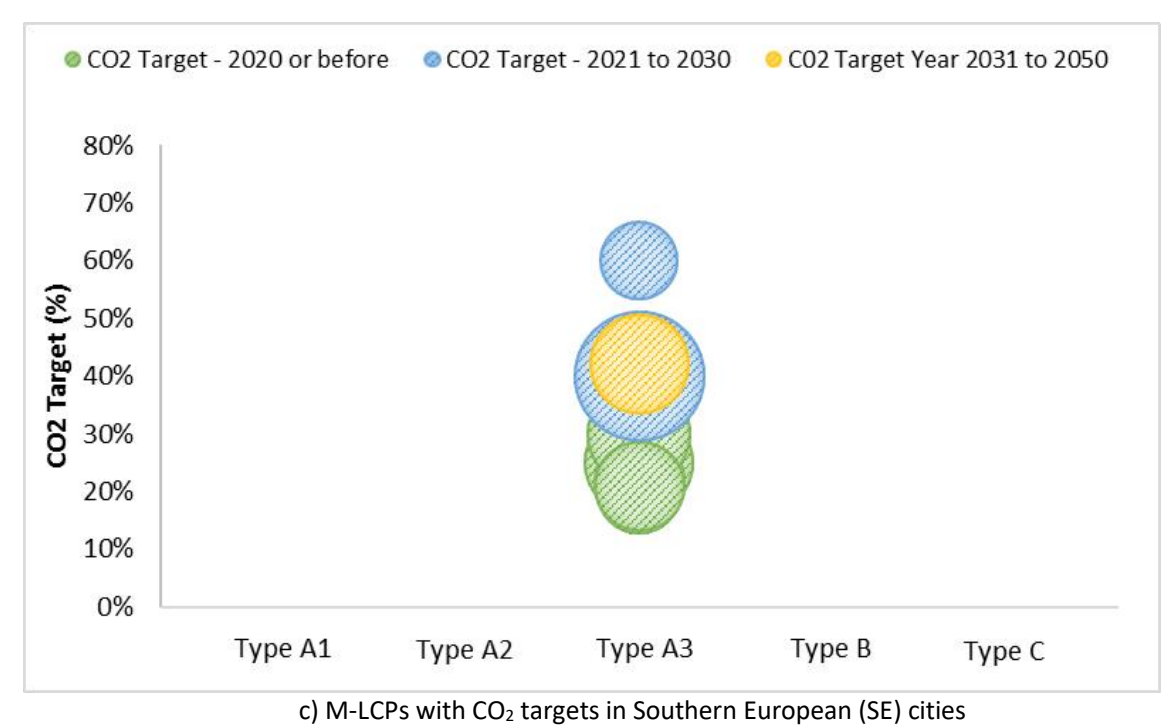

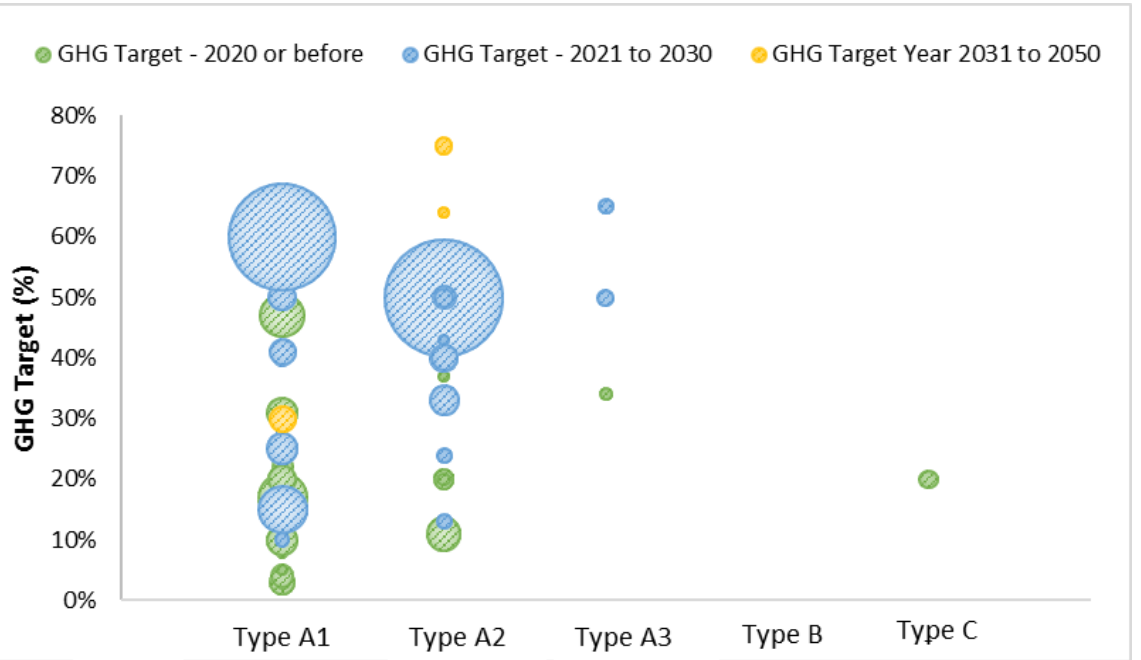

b) M-LCPs with GHG targets $\left(\mathrm{CO}_{2}\right.$ eq) in Northern European (NE) cities

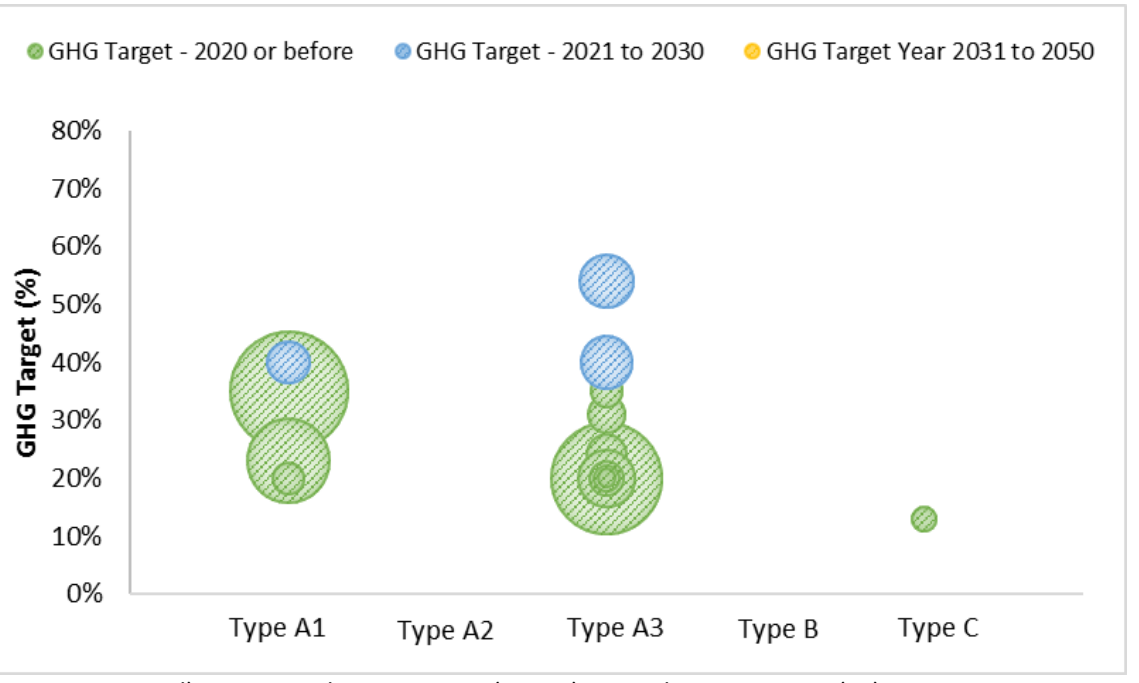

d) M-LCPs with GHG targets ( $\mathrm{CO}_{2}$ eq) in Southern European (SE) cities

Figure 4: Distribution of M-LCPs across their type (A1, A2, A3, B, C), target (\%), type of target $\left(\mathrm{CO}_{2}, \mathrm{GHG}\right)$ and timeline (2020 or before, 2021 to 2030, 2031 to 2050) for different parts of the EU. The city-population covered in the corresponding M-LCPs is represented in relative terms by the size of the bubbles. 
The timeline adopted by cities with a maximum target of less than $80 \%$ also ranges between short (i.e. 2020 or before), medium (i.e. 2021 to 2030) and longer-term periods (i.e. 2031 to 2050). The vast majority, regardless of their type, geographical jurisdiction or ambition level seem to adopt a short to mid-term timeframe, setting targets towards 2020 or 2030 . Only $4 \%$ of those (i.e. 10 cities) have opted for a longerrun timeframe towards 2050 and with varying levels of ambition. These observations strengthen the argument mentioned above that most of the cities present a modest mitigation pledge that is likely to be driven by the European 20-20-20 goal and more recently by the EU 2030 climate and energy framework. The clear lack of longer timelines towards 2050 across these M-LCPs may also indicate that local actions and ambitions are highly dependent on national or regional responses to the Paris Agreement.

The outcome of a correlation analysis between mitigation targets and urban population, climate membership, type of plan and combination of adaptation and mitigation issues highlights potential influences on the level of the emissions reduction targets (Table 3). Table 3 shows that larger cities have higher, i.e. more ambitious, targets. However, population also influences a range of other factors, such as network membership (this applies to all three networks investigated), and type of M-LCP. Regarding type, A1 M-LCPs are particularly numerous in large cities $(a=0.139, p<0.007)$, while A3 LCPs are significantly less prevalent $(a=-0.104, p<0.042)$.

Regarding international climate networks, results reveal that signatories to the Covenant of Mayors (CoM) are correlated with having GHG targets $(\mathrm{a}=0.180, \mathrm{p}<0.034)$, members of $\mathrm{C} 40$ with both $\mathrm{CO}_{2}$ and GHG targets $(a=0.186, p<0.003$; but not either one), and cities involved in the Climate Alliance with all targets $\left(\mathrm{CO}_{2}, \mathrm{GHG}\right.$, combined and separately). This reflects the fact that some climate networks determine the accounting basis $\left(\mathrm{CO}_{2}\right.$ or $\left.\mathrm{CO}_{2} \mathrm{eq}\right)$, while others do not. Membership of any climate network is associated with higher mitigation ambition.

Plans that combine adaptation and mitigation issues show a correlation with the ambition of the $\mathrm{CO}_{2}$ target $(a=0.197, p<0.004)$ and to carbon neutrality $(a=0.111, p<0.038)$. As regards types of plans, only Type A1 plans are related with high mitigation ambition, particularly the $\mathrm{CO}_{2}$ target $(a=0.298, p<0.000)$ as well as carbon neutrality $(a=0.207, p<0.007)$. On the contrary Type A3 M-LCPs are related with low mitigation ambition, negatively correlating with $\mathrm{CO}_{2}$ targets $(a=0.238, p<0.000)$ and with carbon neutrality $(a=0.196$, $\mathrm{p}<0.000$ ). Overall, Table 3 shows that the height of the mitigation ambition is significantly positively related to population size of a city $(a=0.163, p<0.000)$, the membership of climate networks, particularly C40 $(a=0.138, p<0.009)$ and Climate Alliance $(a=0.278, p<0.000)$, combining Adaptation-Mitigation in MLCPs $(a=0.150, p<0.005)$, and Type A1 M-LCPs $(a=0.236, p<0.000)$, while it is negatively correlated with Type A3 M-LCPs $(a=-0.223, p<0.000)$. 
Table 3: Correlation results

\begin{tabular}{|c|c|c|c|c|c|c|c|c|c|c|c|c|c|c|c|}
\hline & $\begin{array}{c}\text { Max } \\
\text { CO2_target }\end{array}$ & $\begin{array}{c}\text { Max } \\
\text { GHG_ } \\
\text { target }\end{array}$ & $\begin{array}{c}\text { Carbon } \\
\text { Neutrality }\end{array}$ & $\begin{array}{c}\text { Max } \\
\text { CO2_GHG } \\
\text { target }\end{array}$ & $\begin{array}{c}\text { CO2_GHG } \\
\text { _CN } \\
\text { Target }\end{array}$ & $\begin{array}{l}\text { Populat } \\
\text { ion }\end{array}$ & CoM & C40 & CA & $\begin{array}{c}\text { A-M } \\
\text { Combine } \\
\text { d }\end{array}$ & TypeA1 & TypeA2 & TypeA3 & TypeB & TypeC \\
\hline \multirow[t]{2}{*}{ Max CO2_target } & 1.000 &. & $.520^{* *}$ & $.995^{* *}$ & $.801^{* *}$ & $.229^{* *}$ & -.054 & .095 & $.348^{* *}$ & $.197^{* *}$ & $.298^{* *}$ & -.079 & $-.283^{* *}$ & -.005 & .039 \\
\hline & . & . & .000 & .000 & .000 & .000 & .429 & .162 & .000 & .004 & .000 & .248 & .000 & .946 & .570 \\
\hline \multirow[t]{2}{*}{ Max GHG_target } & & 1.000 & $.452^{* *}$ & $1.000^{* *}$ & $.819^{* *}$ & $.169^{*}$ & $.180^{*}$ & .118 & $.339^{* *}$ & .024 & .079 & .049 & -.101 & . & -.133 \\
\hline & & . & .000 & . & .000 & .016 & .034 & .165 & .000 & .782 & .353 & .564 & .236 & . & .118 \\
\hline \multirow[t]{2}{*}{ Max CO2_GHG target } & & & & $.489^{* *}$ & $.689^{* *}$ & $.178^{* *}$ & -.001 & $.186^{* *}$ & $.341^{* *}$ & .103 & $.405^{* *}$ & -.069 & $-.381^{* *}$ & -.043 & .051 \\
\hline & & & & .000 & .000 & .001 & .982 & .003 & .000 & .104 & .000 & .271 & .000 & .491 & .422 \\
\hline \multirow[t]{2}{*}{ Carbon Neutrality } & & & & 1.000 & $.808^{* *}$ & $.193^{* *}$ & .054 & .103 & $.343^{* *}$ & $.111^{*}$ & $.207^{* *}$ & -.016 & $-.196^{* *}$ & -.002 & -.016 \\
\hline & & & & & .000 & .000 & .308 & .054 & .000 & .038 & .000 & .768 & .000 & .967 & .758 \\
\hline \multirow[t]{2}{*}{ CO2_GHG_CN Target } & & & & & 1.000 & $.163^{* *}$ & .096 & $.138^{* *}$ & $.278^{* *}$ & $.150^{* *}$ & $.236^{* *}$ & -.024 & $-.223^{* *}$ & -.011 & -.002 \\
\hline & & & & & . & .000 & .072 & .009 & .000 & .005 & .000 & .650 & .000 & .832 & .965 \\
\hline \multirow[t]{2}{*}{ Population } & & & & & & 1.000 & $.265^{* *}$ & $.262^{* *}$ & $.154^{* *}$ & .083 & $.139^{* *}$ & -.041 & $-.104^{*}$ & -.035 & -.012 \\
\hline & & & & & & . & .000 & .000 & .001 & .105 & .007 & .429 & .042 & .491 & .819 \\
\hline \multirow[t]{2}{*}{ CoM } & & & & & & & 1.000 & $.158^{* *}$ & -.042 & -.014 & $-.409^{* *}$ & -.077 & $.432^{* *}$ & .036 & .109 \\
\hline & & & & & & & . & .004 & .453 & .821 & .000 & .220 & .000 & .570 & .083 \\
\hline \multirow[t]{2}{*}{$\mathrm{C} 40$} & & & & & & & & 1.000 & -.047 & -.024 & .043 & -.056 & -.017 & -.016 & .042 \\
\hline & & & & & & & & . & .399 & .703 & .498 & .372 & .786 & .802 & .501 \\
\hline \multirow[t]{2}{*}{ CA } & & & & & & & & & 1.000 & -.087 & $.357^{* *}$ & $-.151^{*}$ & $-.245^{* *}$ & -.028 & -.026 \\
\hline & & & & & & & & & . & .168 & .000 & .016 & .000 & .661 & .677 \\
\hline \multirow[t]{2}{*}{ A-M Combined } & & & & & & & & & & 1.000 & -.059 & $.518^{* *}$ & $-.316^{* *}$ & .094 & -.037 \\
\hline & & & & & & & & & & . & .347 & .000 & .000 & .137 & .559 \\
\hline \multirow[t]{2}{*}{ TypeA1 } & & & & & & & & & & & 1.000 & $-.373^{* *}$ & $-.686^{* *}$ & -.057 & $-.173^{* *}$ \\
\hline & & & & & & & & & & & . & .000 & .000 & .367 & .006 \\
\hline \multirow[t]{2}{*}{ TypeA2 } & & & & & & & & & & & & 1.000 & $-.314^{* *}$ & -.026 & -.079 \\
\hline & & & & & & & & & & & & . & .000 & .680 & .208 \\
\hline \multirow[t]{2}{*}{ TypeA3 } & & & & & & & & & & & & & 1.000 & -.048 & $-.146^{*}$ \\
\hline & & & & & & & & & & & & & . & .447 & .021 \\
\hline \multirow[t]{2}{*}{ TypeB } & & & & & & & & & & & & & & 1.000 & -.012 \\
\hline & & & & & & & & & & & & & & . & .848 \\
\hline TypeC & & & & & & & & & & & & & & & 1.000 \\
\hline
\end{tabular}


However, as all parameters are highly correlated to population size, further tests on these relationships seem necessary. Table 4 shows these results, highlighting that none of the correlations remain significant, which means that all the influential factors of mitigation ambition identified are mainly driven by population size. Thus, even though nationally induced plans, plans boosted by the adhesion to climate networks and combined Adaptation-Mitigation strategies lead to higher mitigation targets than plans that do not share these characteristics, results show that those are mainly found in larger cities (Table 4). 
Table 4: Results of partial correlation, controlling for population, i.e. size of a city in terms of population

\begin{tabular}{|c|c|c|c|c|c|c|c|c|c|c|c|}
\hline & Carbon_neutrality & $\begin{array}{c}\text { CO2_GHG_CN_tar } \\
\text { get }\end{array}$ & AM_Combi & CoM & C40 & CA & TypeA1 & TypeA2 & TyреАЗ & TypeB & TypeC \\
\hline \multirow[t]{2}{*}{ Carbon_neutrality } & 1.000 & .920 & .079 & -.025 & .108 & .339 & .399 & -.079 & -.371 & -.040 & .056 \\
\hline & & .000 & .211 & .696 & .089 & .000 & .000 & .212 & .000 & .524 & .376 \\
\hline CO2_GHG_CN_tar & .920 & 1.000 & .168 & .041 & .099 & .347 & .318 & .005 & -.340 & -.036 & .032 \\
\hline get & .000 & & .008 & .515 & .117 & .000 & .000 & .941 & .000 & .573 & .618 \\
\hline \multirow[t]{2}{*}{ AM_Combi } & .079 & .168 & 1.000 & -.031 & -.137 & -.097 & -.071 & .516 & -.307 & .098 & -.034 \\
\hline & .211 & .008 & . & .620 & .029 & .125 & .264 & .000 & .000 & .123 & .588 \\
\hline \multirow[t]{2}{*}{ CoM } & -.025 & .041 & -.031 & 1.000 & .083 & -.130 & -.426 & -.083 & .452 & .039 & .114 \\
\hline & .696 & .515 & .620 & . & .189 & .040 & .000 & .192 & .000 & .537 & .070 \\
\hline \multirow[t]{2}{*}{ C40 } & .108 & .099 & -.137 & .083 & 1.000 & -.112 & .001 & -.104 & .050 & -.005 & .070 \\
\hline & .089 & .117 & .029 & .189 & . & .077 & .992 & .099 & .432 & .942 & .269 \\
\hline \multirow[t]{2}{*}{ CA } & .339 & .347 & -.097 & -.130 & -.112 & 1.000 & .357 & -.155 & -.242 & -.027 & -.026 \\
\hline & .000 & .000 & .125 & .040 & .077 & . & .000 & .014 & .000 & .671 & .685 \\
\hline \multirow[t]{2}{*}{ TypeA1 } & .399 & .318 & -.071 & -.426 & .001 & .357 & 1.000 & -.379 & -.682 & -.056 & -.172 \\
\hline & .000 & .000 & .264 & .000 & .992 & .000 & & .000 & .000 & .381 & .006 \\
\hline \multirow[t]{2}{*}{ TyреA2 } & -.079 & .005 & .516 & -.083 & -.104 & -.155 & -.379 & 1.000 & -.312 & -.025 & -.079 \\
\hline & .212 & .941 & .000 & .192 & .099 & .014 & .000 & . & .000 & .691 & .214 \\
\hline \multirow[t]{2}{*}{ ТуреА3 } & -.371 & -.340 & -.307 & .452 & .050 & -.242 & -.682 & -.312 & 1.000 & -.050 & -.149 \\
\hline & .000 & .000 & .000 & .000 & .432 & .000 & .000 & .000 & & .429 & .018 \\
\hline \multirow[t]{2}{*}{ TypeB } & -.040 & -.036 & .098 & .039 & -.005 & -.027 & -.056 & -.025 & -.050 & 1.000 & -.013 \\
\hline & .524 & .573 & .123 & .537 & .942 & .671 & .381 & .691 & .429 & . & .841 \\
\hline \multirow[t]{2}{*}{ TypeC } & .056 & .032 & -.034 & .114 & .070 & -.026 & -.172 & -.079 & -.149 & -.013 & 1.000 \\
\hline & .376 & .618 & .588 & .070 & .269 & .685 & .006 & .214 & .018 & .841 & \\
\hline
\end{tabular}




\subsection{Carbon neutrality targets}

Eighty-one (25\%) of the 327 European cities in this sample strive for carbon neutrality (Table 2). This is defined as targets for at least $80 \%$ emissions reductions by 2050 or sooner, in accordance with the Carbon Neutral Cities Alliance (CNCA) definition [4]. This number includes quantitative targets as stated in the plans (which are higher or equal to $80 \%$ emissions reduction) as well as a qualitative statement of the goal in the plan (e.g. "in the long-term CITY aspires towards carbon neutrality"). If the target of carbon neutrality was qualitatively mentioned it is assumed that this equals at least $90 \%$ emissions reduction (the average between $80-100 \%$ ). As stated earlier, Carbon Neutrality does have various definitions and although all care has been taken to standardise the data and analysis it is inevitable that cities will have different understandings of the term carbon neutrality. In this study it was assumed that the term itself was not needed, but the ambition to reduce GHG by $80-100 \%$ would be considered carbon neutral. An analysis of the feasibility or effectiveness of any follow-on steps (in particular offsetting GHG emissions) that some cities might undertake in order to achieve these objectives, was not part of the study .

Most cities that strive to become carbon neutral (CN) aim to do so by 2050 (59 cases, i.e. $73 \%$ ). The remaining 22 set an earlier target date, some as early as 2020, and the average target year is 2045 . An interesting case is Uppsala in Sweden, which aims at reducing $90 \%$ of its emissions by 2040 , more than $100 \%$ by 2050 , and $110 \%$ by 2070 . Other cities that aim to reach carbon neutrality before 2050 include 2 of the 4 Danish cities in the sample (Aarhus and Copenhagen, with a target year of 2030 and 2025, respectively); the Finnish cities of Turku (2029) and Oulu (2040); Göttingen in Germany (2040); the British cities of Birmingham, Exeter, Glasgow, Leicester and Newcastle (all of them referring to 2030); 6 Dutch cities, i.e. Utrecht (2030), Groningen (2035), Den Haag (2040), Breda (2044), Tilburg and Nijmegen (2045); as well as the Swedish cities of Malmö (2020), Linköping (2025), and Stockholm (2040), and Örebro (2045). These findings suggest that local mitigation targets are influenced by national incentives or characteristics.

Indeed, results show that clear geographical patterns emerge in the distribution of GHG reduction targets. German cities have the largest share (27 cities, representing 33.3\% of all German cities in the sample) of carbon-neutral M-LCPs, followed by the UK (13.6\%), the Netherlands (11.1\%) and France (9.9\%). To better understand the magnitude of this movement it is interesting to compare the number of carbon-neutral cities in the sample with the total number of cities analysed by country. The most ambitious plans were developed by Northern and Western European cities: Denmark is at the forefront (i.e. all the 4 reviewed Danish cities aim to become carbon neutral) followed by Finland and Sweden (75\% of them), Germany (68\%), the Netherlands (60\%) and Belgium (57\%). Fewer Austrian (20\%), Irish (20\%), French (23\%), and UK (37\%) cities aim for carbon neutrality. On the other hand, in half of the countries analysed (14), not a single city expresses this level of mitigation ambition. The results show that cities in western EU countries have set much more ambitious mitigation targets compared to cities from the rest of Europe.

Table 5: Overview of cities in our sample striving for carbon neutrality

\begin{tabular}{|c|c|c|c|c|c|}
\hline Countries & $\begin{array}{l}\text { CN cities } \\
\text { (No.) }\end{array}$ & & $\begin{array}{l}\text { Share of CN cities } \\
\text { (\%) }\end{array}$ & $\begin{array}{c}\text { Cities in the sample } \\
\text { (No.) }\end{array}$ & $\begin{array}{c}\text { Share of CN cities by country } \\
\text { (\%) }\end{array}$ \\
\hline Austria & & 1 & $1.2 \%$ & 5 & $20.0 \%$ \\
\hline Belgium & & 4 & $4.9 \%$ & 7 & $57.1 \%$ \\
\hline Bulgaria & & 0 & & 8 & $0.0 \%$ \\
\hline Croatia & & 0 & & 5 & $0.0 \%$ \\
\hline Cyprus & & 0 & & 1 & $0.0 \%$ \\
\hline Czech Republic & & 0 & & 14 & $0.0 \%$ \\
\hline Denmark & & 4 & $4.9 \%$ & 4 & $100.0 \%$ \\
\hline Estonia & & 0 & & 2 & $0.0 \%$ \\
\hline Finland & & 3 & $3.7 \%$ & 4 & $75.0 \%$ \\
\hline
\end{tabular}




\begin{tabular}{lrrrr} 
France & 8 & $9.9 \%$ & 35 & $22.9 \%$ \\
Germany & 27 & $33.3 \%$ & 40 & $67.5 \%$ \\
Greece & 0 & $1.2 \%$ & 9 & $0.0 \%$ \\
Hungary & 1 & $1.2 \%$ & 9 & $11.1 \%$ \\
Ireland & 1 & $3.7 \%$ & 5 & $20.0 \%$ \\
Italy & 3 & 32 & $9.4 \%$ \\
Latvia & 0 & & 2 & $0.0 \%$ \\
Lithuania & 0 & & 3 & $0.0 \%$ \\
Luxembourg & 0 & & 1 & $0.0 \%$ \\
Malta & 0 & 2 & $0.0 \%$ \\
Netherlands & 9 & $11.1 \%$ & 15 & $60.0 \%$ \\
Poland & 0 & & 28 & $0.0 \%$ \\
Portugal & 1 & 9 & $11.1 \%$ \\
Romania & $1.2 \%$ & 14 & $0.0 \%$ \\
Slovakia & & 8 & $0.0 \%$ \\
Slovenia & 0 & 2 & $0.0 \%$ \\
Spain & 0 & & 8 & $8.0 \%$ \\
Sweden & 0 & $2.5 \%$ & 30 & $75.0 \%$ \\
UK & 2 & $13 \%$ & $36.7 \%$ \\
\hline TOTAL & 6 & $100 \%$ & 327 & $2 \%$ \\
\hline
\end{tabular}

The correlation analysis (Table 3 ) shows that carbon neutrality has a significant and positive association with population size $(a=0.193, p<0.000)$, membership of the Climate Alliance network $(a=0.343, p<0.000)$, the combination of adaptation and mitigation aspects in an M-LCP $(a=0.111, p<0.038)$, and Type A1 MLCPs $(a=0.207, p<0.000)$, while it significantly negatively correlates with Type A3 M-LCPs $(a=-0.196$, $p<0.000)$. However, as with the level of mitigation targets discussed in section 3.1, all of these factors are also determined by population size.

The size of the 81 cities that aim to become carbon neutral is highlighted in Table 6, and Figure 5 provides more details on these cities. Table 6 shows that most of the cities that strive to become carbon neutral (60.5\%) have between 100,000 and 500,000 inhabitants, and $24.7 \%$ of them have populations of 500,000 $1,000,000$. This subsample includes, respectively, $50.0 \%$ of the largest cities ( $>1,000,000$ inhabitants) with a M-LCP, $43.2 \%$ of cities that have a population between 500,000 and $1,000,000$ and a M-LCP, $30.4 \%$ of those with a population between $100,000-500,000$ and a M-LCP, $7.1 \%$ of those with a population between $50,000-100,000$, and $33.3 \%$ of smaller cities $(<50,000$ inhabitants) with a M-LCP.

Table 6: Cities with Carbon Neutrality targets, grouped according to city size, and compared to the overall number of cities in the sample and with those with a M-LCP.

\begin{tabular}{|c|c|c|c|c|c|}
\hline \multirow{2}{*}{$\begin{array}{l}\text { City size } \\
\text { (No. of inhabitants) }\end{array}$} & \multirow{2}{*}{$\begin{array}{c}\text { Cities in the sample } \\
\text { (No.) }\end{array}$} & \multicolumn{2}{|c|}{ CN cities } & \multicolumn{2}{|c|}{ Cities with a M-LCP } \\
\hline & & (No.) & (\%) & (No.) & (\%) \\
\hline$>1,000,000$ & 20 & 9 & $11,1 \%$ & 18 & $50,0 \%$ \\
\hline $500,000-1,000,000$ & 45 & 20 & $24,7 \%$ & 44 & $45,5 \%$ \\
\hline $100,000-500,000$ & 206 & 49 & $60,5 \%$ & 161 & $30,4 \%$ \\
\hline $50,000-100,000$ & 51 & 2 & $2,5 \%$ & 28 & $7,1 \%$ \\
\hline$<50,000$ & 5 & 1 & $1,2 \%$ & 3 & $33,3 \%$ \\
\hline TOTAL & 327 & 81 & $100 \%$ & 254 & $31,9 \%$ \\
\hline
\end{tabular}

The colour of the bars in Figure 5 show how $74.1 \%$ of the 81 carbon neutral striving cities in the analysed sample have autonomously developed a mitigation plan (type A1), $11.1 \%$ have set a target under the imposition of their national legislation (M-LCP of type A2), 9.9\% have developed a SEAP/SECAP (type A3) and the remaining $4.9 \%$ has set their GHG emissions reduction target within an energy plan (type C). Moreover, the same figure, provides a graphical representation of the type of plan and of membership of 
the CoM, C40 and CA climate networks for all 81 of the cities that aim to become carbon neutral. It shows that $75.3 \%$ of the analysed cities are members of the Global Covenant of Mayors for Climate and Energy (GCoM), $34.6 \%$ of Climate Alliance, $12.3 \%$ of $\mathrm{C} 40$ and $7.4 \%$ of the Carbon Neutral Cities Alliance (CNCA). More than one-quarter (27.2\%) of these cities are a member of two transnational networks and $4.9 \%$ are involved in three of these international initiatives. 


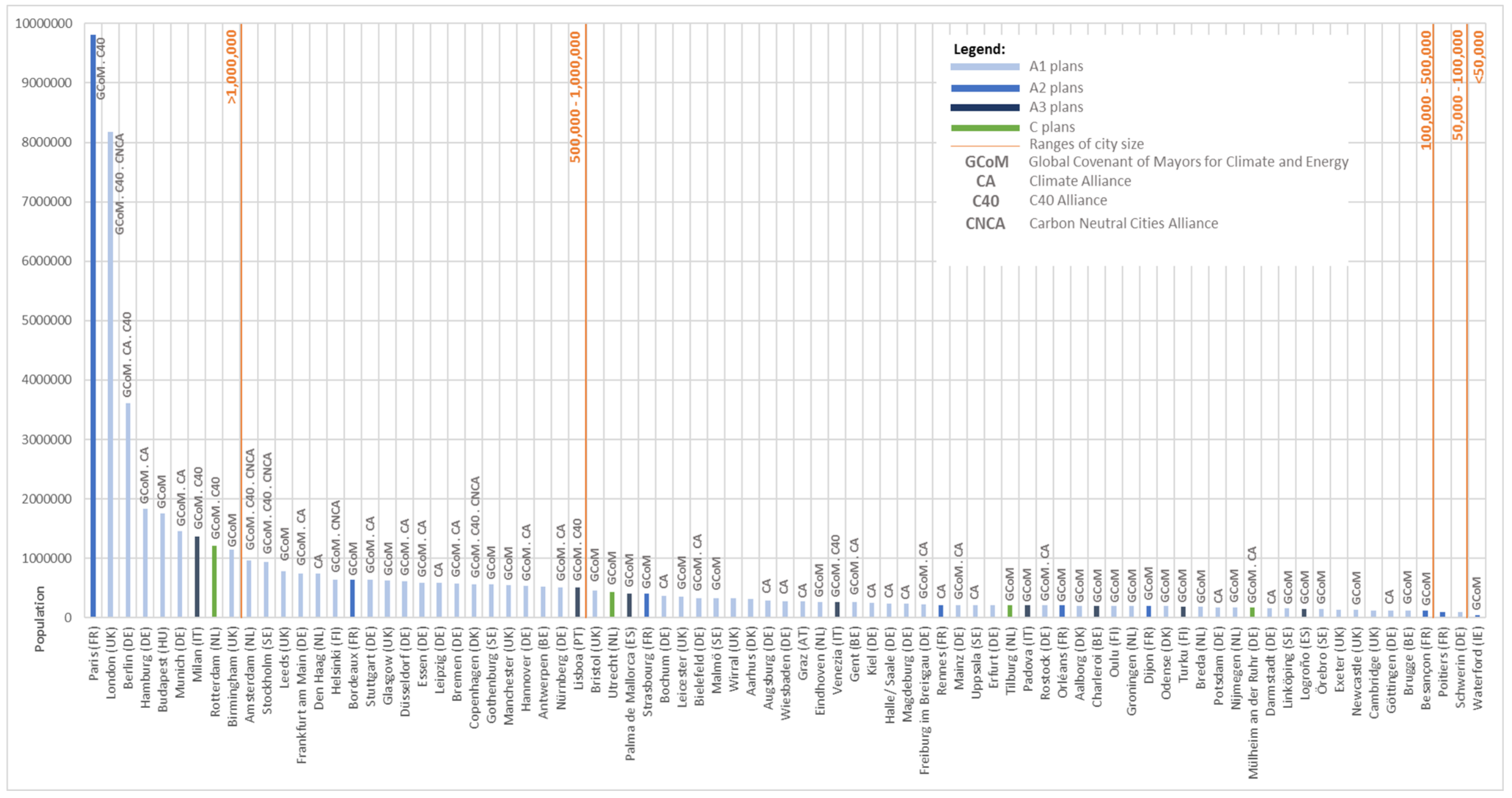

Figure 5: The 81 carbon neutral cities in the overall sample: city size, type of plans and membership to

transnational climate alliances. 


\subsection{Energy targets}

In the analysed cities, $11 \%$ of the mitigation plans set energy efficiency (EE) targets, $11 \%$ set targets on renewable energy sources (RES), and $27.2 \%$ include combined targets for both EE and RES. In contrast, $50.4 \%$ of M-LCPs do not set any energy targets. The reason for such variation across the city sample is that EE and RES targets are generally set by cities in dedicated energy plans (e.g. Municipal Energy Plans).

The M-LCPs analysed in our sample are extremely varied in terms of how energy savings and/or energy efficiency objectives are set. In some cases, the objectives are related to specific sub-sectors, and in others they are set in terms of energy consumption per inhabitant (such as for cities in Denmark, France, Germany and Sweden).

In almost all of the analysed plans, the focus of the targets is on buildings (both municipal and private):M-LCPs anticipate energy retrofits for both the building envelope, and its climate control and sanitary water systems. Another key sector is transport: most of the M-LCPs aim to strengthen public transport services, improve municipal fleets, and expand current cycling lanes. Aalborg and Copenhagen, in Denmark, aim to have all vehicles in their municipal fleet fossil-free by 2050 , replacing traditional fuel with electricity, hydrogen or biofuels. Most of the interventions proposed by cities also deal with public lighting, by aiming to replace lightbulbs with LED technology and improving lighting management and monitoring systems. Aalborg is also considering reducing its use of information and communication technology (ICT) by a minimum of $2 \%$ per year by 2020 and by $50 \%$ by 2050 . In most M-LCPs special attention is given to schools, such as in Leicester (UK), which promotes energy performance contracts to try and reduce consumption and provides advice on more efficient operation of the school building stock. Reducing energy poverty in vulnerable households is a related goal for some cities (such as Exeter and Glasgow in the UK), which are considering lowering taxes to incentivise the installation of EE measures.

This variability in terms of how energy efficiency is incorporated into local mitigation plans also applies to targets for the use of renewable energy sources (RES). In the sample of M-LCPs, these were expressed as a percentage increase (17.3\%), as a share in the final energy consumption $(61.2 \%)$, in terms of sector targets (9.2\%), or by referring to the total electricity and /or heat they intend to produce from RES (12.2\%). Eight Northern European cities in our sample aim to have $100 \%$ of their energy come from RES: Paris and Bordeaux (France), Frankfurt am Main, Göttingen and Augsburg (Germany), Malmö and Uppsala (Sweden), Manchester (UK)). Danish cities aim to increase the share of district heating in local energy provision, and also make it fossil fuel-free and $\mathrm{CO}_{2}$ neutral.

More in-depth analysis of the potential correlations between different cities' EE and RES targets on the one hand, and their climate mitigation ambitions and initiatives on the other, is necessary. However, it was beyond the narrower scope of the study that underpins the findings in this paper.

\section{Discussion}

This section discusses the above presented results regarding the different speeds of climate change planning in different parts of Europe in order to understand how urban-scale climate change policy is being shaped within the EU.

The analysis revealed that $78 \%$ of the small, medium and large cities in the sample have a mitigation plan with targets for reducing greenhouse gas emissions, and $25 \%$ of them strive for carbon neutrality (defined 
as targets for at least $80 \%$ emissions reductions by 2050 or sooner). The average mitigation target of all cities is to reduce GHG by $47 \%$.

These targets show that European cities are not yet on track to comply with the Paris Agreement, which demands net zero emissions by the year 2050 [1]. Therefore, this study supports other research [24,25] that has claimed that many cities lack ambition - at least in terms of the urgency and scale of mitigation and emissions reduction that is required.

There is limited scientific literature on the carbon neutrality of municipalities. However, the findings of this study reflect those of similar research into the most ambitious countries in Europe on the subject of carbon neutrality. For example, a study in Denmark (a climate leader, and the country with the lowest energy intensity in the European Union) showed that only about $20 \%$ of municipalities in Denmark want to become total fossil free or carbon neutral [47].

The average year for reaching carbon neutrality is 2045, with twenty-two cities aiming for it earlier than 2050. Malmö (Sweden) aims to be carbon neutral as early as 2020, having adopted a plan to achieve this in 2009. However, the concept was vaguely described and it included options for paying for carbon offsets (compensating for local emissions by funding carbon sinks elsewhere in the world). German cities have the largest number of carbon-neutral M-LCPs in the sample, while Denmark ranks first in terms of national share (all cities in the sample aim to become carbon neutral). This supports other studies that show the leadership role of Denmark in the EU in terms of carbon neutrality aspirations [47].

This study also reveals interesting geographical patterns in terms of those cities that are aiming for carbon neutrality. The most ambitious cities are those in Northern and Western Europe (ranging from 100\% in the case of Danish cities to $43 \%$ in the case of the UK), while Southern and Eastern Europe is characterized by lower ambitions (in many of these countries, no city aims to become carbon neutral, although $23 \%$ of French cities have set this target). In line with other studies, countries with a higher level of GDP per capita have more cities that aim to become carbon neutral [27], a greater number of local climate plans, and more far-reaching ambitions [26,32]. However, France is an interesting contradictory case: it has many cities with local climate plans (induced by the national legislation) but relatively low ambition in terms of carbon neutrality. It is also possible to find a "Mediterranean" pattern in which the share of cities aiming for carbon neutrality ranges zero in the Eastern Mediterranean (Cyprus, Croatia, Greece, and Malta), to 23\% in France. Indeed, Western European cities are much more ambitious with respect to mitigation targets than cities in other parts of Europe, which could reflect the overall GHG reduction activity in those countries [32,37].

Overall, the results show that cities with high mitigation targets are mostly larger cities that have A1 MLCPs, combine adaptation and mitigation, and engage in climate networks. However, since city size is the most important predictor of climate mitigation ambition, the role of climate networks in shaping the approaches of smaller cities is unclear. In addition, the dataset does not reveal whether smaller cities that have joined these networks are less ambitious or just more realistic than their counterparts that remain outside. Giest and Howlett [48] suggest that "high-profile" climate networks (such as the C40) could be less effective in fostering "concrete actions compared to regional "in-depth" networks" [49]. It may therefore be the case that different networks play different roles and further research is therefore needed into how they may shape climate policy ambition.

The results also show that local motivation is a good stimulus for climate ambition, as demonstrated by its correlation with A1 M-LCPs and also by the lower level of ambition of French cities that only seek to meet national obligations (see below). However, Southern European cities with less capacity/ GDP may already find it difficult to reach slightly lower mitigation targets. This points to the weakness of providing 
quantitative recommendations, which are usually seen as a maximum instead of a minimum threshold that organisations should aim for. Guidelines could instead focus on providing qualitative advice on how to identify what can be achieved [17].

Controlling for population, the correlations loose significance, implying that smaller cities in general do not have the support of climate networks, lack the capacity to develop joint approaches for adaptation and mitigation, and fail to drive the development of independent Type A1 M-LCPs. As found by others (e.g. $[50,18])$, smaller cities need support from higher tiers of government, as well as other relevant stakeholders. This also indicates that from the activities or smaller cities are to a large extent dependent on national or regional policies.

Most local climate plans within our sample adopt a 2020 or 2030 timeframe, suggesting an inherent dependence on the EU's 20-20-20 targets and the more recent 2030 energy and climate framework. This observation is also in line with the correlation findings regarding the type of plans (e.g. Type A1 M-LCPs). The scarcity of longer-term targets (i.e. beyond 2030) implies that city-level actions and ambition will likely be steered by national and regional pledges, which themselves will be shaped by political will and commitment and the availability of resources.

The energy sector plays a key role in climate mitigation, through "new technologies, energy production with reduced emissions, more efficient energy use" as well as "changed management practices and consumer behaviour" [17]. This is reflected in the common vision of local mitigation action plans, which generally focus on increasing EE and the use of RES. All the plans available in our sample included both EE interventions and RES implementation strategies to reach their emissions limits. Therefore, for some cities, the definition of specific objectives on EE and RES within the M-LCP, in combination with emissions reduction objectives, can strengthen their ability to achieve climate objectives.

The study has limitations. First of all, the UA city sample underrepresents small cities below 50,000 inhabitants. Second, the small number of mainstreamed (B plans) and energy plans ( $C$ plans) in the sample of LCPs does not necessarily represent the overall picture particularly well. As highlighted in Section 2.2, only one M-LCP was selected and analysed in-depth for each city, and priority was given to the A1 comprehensive M-LCPs among other types identified. Thus, B and C plans were examined only in the absence of $\mathrm{A} 1, \mathrm{~A} 2$ or $\mathrm{A} 3$ plans. Moreover, it may be more difficult to find $\mathrm{B}$ or $\mathrm{C}$ plans online than to find A plans (because the keywords are less clear), so the number of cities with B or C plans may be underestimated. Also, plans labelled as A1 (autonomously developed) or A2 (nationally induced) may have been led by an international climate network. To investigate these aspects, data on the availability of MLCPs in this sample was cross-checked with detailed information on each city's current stage of commitment under the Covenant of Mayors for Climate and Energy. This comparison distinguish between two different groups of cities: (a) Cities that generally develop a plan after (and enhanced by) their membership of the CoM. This represents the most frequent case in which the only available M-LCP is a SEAP/SECAP (A3 Type) - 51\% of the cities in our sample fall into this category; (b) Cities that are members of the CoM but developed their plan autonomously and then entered it into the system through the CoM. This applies to the cities falling under Types A1 (34\%), A2 (11\%) and C (4\%). Irish cities, where municipalities are legally bound by planning legislation to implement climate change and other environmental regulations, are an example of cities that are members of the CoM but have developed their A2 plan regardless of their commitment to this network. However, it was also the case for Dutch cities where municipalities are required to draw up a plan to tackle the development of renewable energy (C plans) and where some cities have developed their M-LCP regardless of the commitment made within the CoM (A1 plans). 
Third, government legislation in some countries, such as France, require cities to provide local climate plans at the metropolitan level. For this reason, France has older local LCPs in the sample as well as newer ones. An issue of scale can also be raised for small countries like Malta and Luxembourg, which do not have a plan for the entire UA city area. For example, in the case of Malta several local councils that form part of the urban agglomeration area have submitted plans to the CoM, but these do not cover the entire UA city. Another difficulty is using "city scale" analysis: more and more cities are now designing shared climate plans on a regional scale, so it may be difficult to disentangle city plans from regional plans. This could reflect national approaches on how multi-level climate governance should operate, or be caused by municipalities seeking to team up with other neighbouring rural municipalities to try and reduce costs or build RES-based power and heat plants (e.g. solar and wind farms) away from urban centres. Indeed, many cities are limited in their options to implement climate mitigation measures [51-52], partly due to the physical space at their disposal [53]. Working with neighbouring municipalities may help to address this issue, but it might also result in conflict and delay over production of shared local climate change strategies. In Ireland, the city boundary has been expanded to include several urban areas in recent years [54],reflecting the fact that the spatial scale of some urban climate plans has grown to include entire metropolitan areas or regions.

\section{Conclusions}

This study analysed the climate change mitigation ambition of a representative sample of 327 European cities, including the extent to which they aim to become carbon neutral. It also helped to understand the similarities and differences in the climate planning process in different parts of Europe.

The analysis revealed that $78 \%$ of the cities in the sample have a mitigation plan with mitigation targets. The average mitigation target is $47 \%$ reduction in GHG emissions. Furthermore, 81 cities ( $25 \%$ of the total sample) are striving for carbon neutrality, on average by 2045, although 22 cities aim to achieve this goal earlier, e.g. as early as 2020. Assuming representativeness of the sample, this means that European cities are not yet set up to comply with the Paris Agreement, which requires net zero emissions around the year 2050. In reality, cities must urgently redouble their efforts to meet this target.

The most ambitious cities are those in Northern and Western European countries. In general terms, cities in Southern and Eastern European countries are less likely to have declared an ambition to reach carbon neutrality. Furthermore, the level of mitigation ambition is significantly and positively related to the size of the city and the city's membership of climate networks, in particular C40 and Climate Alliance. However, as the results of this study contrast with those of others, more research is needed on the role of climate networks in mitigation ambition, and potentially implementation and success.

Smaller cities are less ambitious. Only $7.1 \%$ of the cities with a population between $50,000-100,000$ inhabitants have a carbon neutrality target, compared to $32 \%$ on average. Establishing plans at a regional level or through inter-municipal government cooperation could leverage more resources (council staff, population, budget) to develop and implement climate strategies. Indeed, the study also identified the development of mitigation plans at wider jurisdictional levels (e.g. the metropolitan or regional level) as an emerging trend. This approach could help to achieve the much needed increase in mitigation ambition and effort, in order to safeguard a sustainable world in line with the 1.5 degree target. However, further research is needed with regard to the effectiveness of measures and plans at the local, metropolitan and regional level. 
Future research should also evaluate mitigation actions in their effectiveness in reducing GHG emissions. In addition to a city's population, which is a very important determining factor in our study, it will be interesting to explore other potential factors that can contribute to the ambition of the mitigation objectives of cities (such as per capita GDP, unemployment rate, public awareness of climate change, local climate, proximity to the coast, politics, etc.). A more in-depth assessment of the energy targets included in M-LCPs also deserves further attention.

\section{Data availability}

Datasets related to this article can be found at http://dx.doi.org/..., an open-source online data repository hosted at Mendeley Data (Salvia et al., 2020).

\section{Acknowledgements}

We thank council representatives and local technicians that supported the data collection. We also thank the EU COST Action TU0902 (led by Richard Dawson) that established the core research network and the positive engagement and interaction of the members of this extended group.

The paper reflects only the views of the authors. The European Union, the European Environment Agency or other supporting bodies are not liable for any use that may be made of the information that is provided in this manuscript.

Funding: MO's work is funded by AXA Research Fund (No. 4771), by the Spanish Government (IJCl-201628835 and MDM-2017-0714) and by the Basque Government (BERC 2018-2021 program). OH was funded by the EC project RAMSES Reconciling Adaptation, Mitigation and Sustainable Development for Cities (contract Ref 308497) and the EPSRC project LC Transforms: Low Carbon Transitions of Fleet Operations in Metropolitan Sites Project (EP/N010612/1).

\section{Declarations of Interest}

Aoife Foley, is a co-author on this paper and as the Editor in Chief of RSER, she was blinded to this paper during the review process, and the paper was independently handled by Taehoon Hong. 


\section{References}

[1] Masson-Delmotte V, Zhai P, Pörtner H-O, Roberts D, Skea J, Shukla PR, et al. IPCC, 2018: Summary for Policymakers. In: Global Warming of $1.5^{\circ} \mathrm{C}$. An IPCC Special Report on the impacts of global warming of $1.5^{\circ} \mathrm{C}$ above pre-industrial levels and related global greenhouse gas emission pathways, in the context of strengthening the global. Geneva: 2018.

[2] Van Der Schoor T, Scholtens B. Power to the people: Local community initiatives and the transition to sustainable energy. Renew Sustain Energy Rev 2015;43:666-75.

[3] British Standards Institution 2014. PAS 2060:2014 Specification for the demonstration of carbon neutrality. BSI Standards Limited 2014; 2014.

[4] CNCA. Carbon Neutral Cities Alliance 2019. https://carbonneutralcities.org/about/ [accessed 19 February 2020].

[5] Swedish Government. Ett klimatpolitiskt ramverk för Sverige (A Climate Policy Framework for Sweden). Bill 2016/17:146, approved by the Swedish Parliament, 15 June 2017. 2017.

[6] Ministere de la Transition ecologique et solidaire. Plan Climat. France: 2017.

[7] UK Government. UK becomes first major economy to pass net zero emissions law - GOV.UK 2019. https://www.gov.uk/government/news/uk-becomes-first-major-economy-to-pass-net-zeroemissions-law [accessed 19 February 2020].

[8] Ministry for the Environment. Climate Change Response (Zero Carbon) Amendment Act. New Zealand: 2019.

[9] UNFCC. Costa Rica Commits to Fully Decarbonize by 2050 2019. https://unfccc.int/news/costarica-commits-to-fully-decarbonize-by-2050 [accessed 19 February 2020].

[10] European Parliament. Resolution on climate change - a European strategic long-term vision for a prosperous, modern, competitive and climate neutral economy in accordance with the Paris Agreement. vol. 2160. Europe: 2019.

[11] European Parliament. Directive (EU) 2018/2001 of the European Parliament and of the Council on the promotion of the use of energy from renewable sources. 2018.

[12] Betsill MM, Bulkeley H. Cities and the Multilevel Governance of Global Climate Change. Glob Gov 2016;12:141-59.

[13] Jänicke $M$, Wurzel RKW. Leadership and lesson-drawing in the European Union's multilevel climate governance system. Env Polit 2019;28:22-42.

[14] Hsu A, Höhne N, Kuramochi T, Roelfsema M, Weinfurter A, Xie Y, et al. A research roadmap for quantifying non-state and subnational climate mitigation action. Nat Clim Chang 2019;9:11-7.

[15] Di Gregorio M, Fatorelli L, Paavola J, Locatelli B, Pramova E, Nurrochmat DR, et al. Multi-level governance and power in climate change policy networks. Glob Environ Chang 2019;54:64-77.

[16] Kern K, Alber G. OECD Conference Proceedings. Chapter 8: Governing Climate Change in Citites: Modes of Urban Climate Governance in Multi-level Systems. Compet. Citites Clim. Chang., Milan: 2008, p. 171-96.

[17] Mendizabal M. Heidrich O, Feliu E, García-Blanco G, Mendizabal A. Stimulating urban transition and transformation to achieve sustainable and resilient cities. Renew Sustain Energy Rev 2018;94:410-418. 
[18] Kern K. Cities as leaders in EU multilevel climate governance: embedded upscaling of local experiments in Europe. Env Polit 2019;28:125-45.

[19] Eckersley P, Tobin P. The impact of austerity on policy capacity in local government. Policy Polit 2019;47:455-72.

[20] UNEP - UN Environment Programme. Mitigation 2019. https://www.unenvironment.org/exploretopics/climate-change/what-we-do/mitigation [accessed 19 February 2020].

[21] Rosenzweig C, Solecki W, Hammer SA, Mehrotra S. Cities lead the way in climate-change action. Nature 2010;467:909-11.

[22] Broto VC, Bulkeley H. A survey of urban climate change experiments in 100 cities. Glob Environ Chang 2013.

[23] United Nations. Climate Action Summit Delivers Major Step-Up in National Ambition, Private Sector Initiatives on Pathway to Key 2020 Deadline | Meetings Coverage and Press Releases 2019. https://www.un.org/press/en/2019/envdev1998.doc.htm [accessed 19 February 2020].

[24] Bansard JS, Pattberg PH, Widerberg O. Cities to the rescue? Assessing the performance of transnational municipal networks in global climate governance. Int Environ Agreements Polit Law Econ 2017;17:229-46.

[25] van der Heijden J, Patterson J, Juhola S, Wolfram M. Special section: advancing the role of cities in climate governance-promise, limits, politics. J Environ Plan Manag 2019;62:365-73.

[26] Reckien D, Salvia M, Heidrich O, Church JM, Pietrapertosa F, De Gregorio-Hurtado S, et al. How are cities planning to respond to climate change? Assessment of local climate plans from 885 cities in the EU-28. J Clean Prod 2018;191:207-19.

[27] Reckien $D$, Flacke J, Olazabal M, Heidrich $O$. The influence of drivers and barriers on urban adaptation and mitigation plans-an empirical analysis of European Cities. PLoS One 2015;10:121.

[28] Heikkinen M, Karimo A, Klein J, Juhola S, Ylä-Anttila T. Transnational municipal networks and climate change adaptation: A study of 377 cities. J Clean Prod 2020;257:120474.

[29] Climate Alliance. Climate Alliance. Review and outlook 2017-2018. 2018.

[30] C40 Cities. www.c40.org [accessed 26 January 2020].

[31] Covenant of Mayors for Climate and Energy. https://www.covenantofmayors.eu/ [accessed 16 January 2020]

[32] Reckien D, Salvia M, Pietrapertosa F, Simoes SG, Olazabal M, De Gregorio Hurtado S, et al. Dedicated versus mainstreaming approaches in local climate plans in Europe. Renew Sustain Energy Rev 2019;112:948-59.

[33] Shaw A, Burch S, Kristensen F, Robinson J, Dale A. Accelerating the sustainability transition: Exploring synergies between adaptation and mitigation in British Columbian communities. Global Environ Chang 2014;25:41-51.

[34] Göpfert C, Wamsler C, Lang W. A framework for the joint institutionalization of climate change mitigation and adaptation in city administrations. Mitig Adapt Strateg Glob Change 2018;1-21.

[35] Shrestha S, Dhakal S. An assessment of potential synergies and trade-offs between climate mitigation and adaptation policies of Nepal. J Environ Manage 2019;235:535-545.

[36] Spencer B, Lawler J, Lowe C, Thompson L, Hinckley T, Kim S-H, et al. Case studies in co-benefits approaches to climate change mitigation and adaptation. J Environ Plann Man 2017;60:647-667. 
[37] Reckien D, Flacke J, Dawson RJ, Heidrich O, Olazabal M, Foley A, et al. Climate change response in Europe: what's the reality? Analysis of adaptation and mitigation plans from 200 urban areas in 11 countries. Clim Change 2014;122:331-40.

[38] Olazabal M, Hurtado SDG, Olazabal E, Pietrapertosa F, Salvia M, Geneletti D, et al. How are Italian and Spanish cities tackling climate change ? A local comparative study. 2014.

[39] Statistical Office of the European Communities. Database - Eurostat 2019. https://ec.europa.eu/eurostat/web/cities/data/database [accessed 23 September, 2019].

[40] Pas-de-calais FRN, Lorraine FR. Annex 1 NUTS (nomenclature of territorial units for statistics) European Union : NUTS 2 regions, 2010.

[41] Eurostat. Urban Audit Methodological Handbook. Luxembourg: 2004.

[42] Eurostat. Annex 2 - Cities participating in the Urban Audit data collection. 2015.

[43] Eurostat. Methodological Manual on City Statistics. 2017.

[44] The Covenant of Mayors for Climate and Energy. The Covenant of Mayors for Climate and Energy Reporting Guidelines, https://www.covenantofmayors.eu/IMG/pdf/Covenant_ReportingGuidelines.pdf [accessed 23 September, 2019].

[45] Laerd statistics. Kendall's Tau-b using SPSS Statistics - A How-To Statistical Guide by Laerd Statistics 2020. https://statistics.laerd.com/spss-tutorials/kendalls-tau-b-using-spss-statistics.php [accessed 20 March 2020].

[46] Laerd statistics. Partial Correlation in SPSS Statistics - Procedure, assumptions, and output using a relevant example. 2020. https://statistics.laerd.com/spss-tutorials/partial-correlation-using-spssstatistics.php [accessed 20 March 2020].

[47] Dams $\varnothing$ T, Kjær T, Christensen TB, Implementation of local climate action plans: Copenhagen Towards a carbon-neutral capital. J Clean Prod 2017;167:406-415.

[48] Giest S, Howlett M. Comparative Climate Change Governance: Lessons from European Transnational Municipal Network Management Efforts. Environ Policy Gov 2013;23:341-53.

[49] Steffen B, Schmidt TS, Tautorat P. Measuring whether municipal climate networks make a difference: the case of utility-scale solar PV investment in large global cities. Clim Policy 2019;19:908-22.

[50] Franzén M. Local governments as nodes for greenhouse gas abatement: Climate change governance in multi-level frameworks. Eur J Sustain Dev 2013;2:361-372.

[51] Wilson RW, Brown KD. Carbon Neutrality at the Local Level: Achievable Goal or Fantasy? J Am Plann Assoc, 2008;74:4:497-504.

[52] Chen G, Shan Y, Hu Y, Tong K, Wiedmann T, Ramaswami A, et. al. Review on City-Level Carbon Accounting. Environ. Sci. Technol. 2019;53,10:5545-5558.

[53] Ghag J. A ticking time bomb? Liverpool declares a climate emergency: What next? Environ Law Rev 2019;21:169-72.

[54] Department of the Environment and Local Government. Spatial Planning Unit - National Spatial Strategy. The Irish Urban System and its Dynamics. 2020 http://www.irishspatialstrategy.ie/docs/report8.pdf [accessed 20 May 2020]. 
[1] [dataset] Salvia et al., Climate mitigation ambition towards carbon neutrality? An analysis of local-level plans of 327 cities in the EU: Datasets and Supplementary Materials, 2020, Mendeley Data, v0, http://dx.doi.org/xxx. 